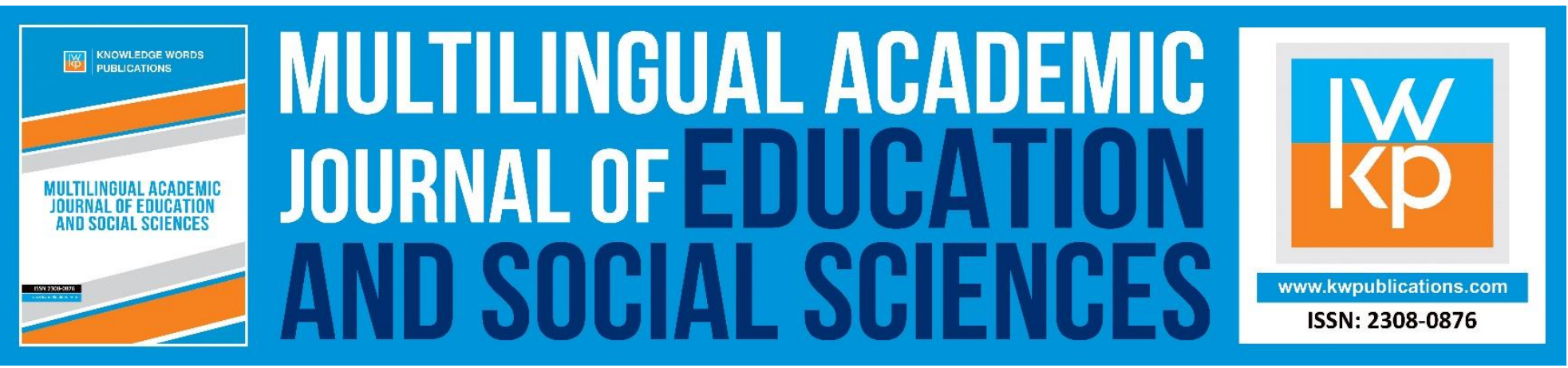

\title{
"Yes, We Can" by Will. I. Am. Music Video or Political Propaganda?
}

\section{Georgia Tsampra \& May Kokkidou}

To Link this Article: http://dx.doi.org/10.46886/MAJESS/v8-i1/6961

DOI:10.46886/MAJESS/v8-i1/6961

Received: 02 January 2020, Revised: 05 February 2020, Accepted: 28 February 2020

Published Online: 18 March 2020

In-Text Citation: (Tsampra \& Kokkidou, 2020)

To Cite this Article: Tsampra, G., \& Kokkidou, M. (2020). "Yes, We Can" by Will. I. Am. Music Video or Political Propaganda?. Multilingual Academic Journal of Education and Social Sciences, 8(1), 1-17.

\section{Copyright: (c) The Authors 2020}

Published by Knowledge Words Publications (www.kwpublications.com)

This article is published under the Creative Commons Attribution (CC BY 4.0) license. Anyone may reproduce, distribute, translate and create derivative works of this article (for both commercial and non-commercial purposes), subject to full attribution to the original publication and authors. The full terms of this license may be seen at: http://creativecommons.org/licences/by/4.0/legalcode

\section{Vol. 8, No. 1, 2020, Pg. 1 - 17}




\title{
"Yes, We Can" by Will. I. Am. Music Video or Political Propaganda?
}

\author{
Georgia Tsampra \& May Kokkidou \\ European University Cyprus
}

\begin{abstract}
The present article investigates the polysemic world of audiovisual digital objects of popular culture, using as a case study the video "Yes, We Can" which has been produced by the popular music producer and song writer will.i.am. "Yes, We Can" is a mashup music video which includes excerpts from Barack Obama's campaign speech (2008 pre-election campaign), featuring many celebrities. The analysis (decoding and interpretation) of "Yes, We Can" is based on a new synthetic multimodal model, following the premise that in every audiovisual object, language, image, sound and music interact dynamically, creating multiple levels of meaning. Our multimodal analysis focuses on the synergy of the video's semantic systems, its communication potential and aesthetic identity. According to our results, "Yes, We Can" differs from conventional music videos and can be considered as a special genre of music-political video which makes organic use of music video language in order to express social-political messages. Another conclusion is that our model is a functional one enabling the emergence of hidden meanings of a music video.
\end{abstract}

Keywords: Codes, Music Video, Political Video, "Yes, We Can”, Multimodal Analysis.

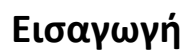

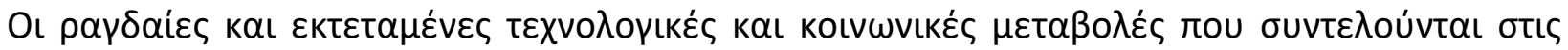

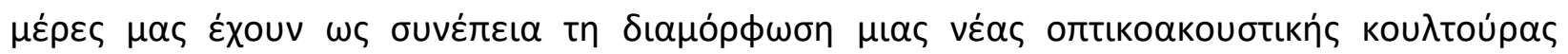

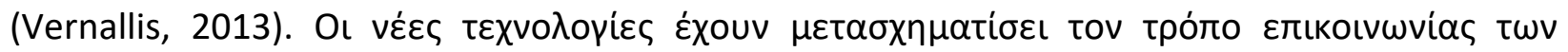

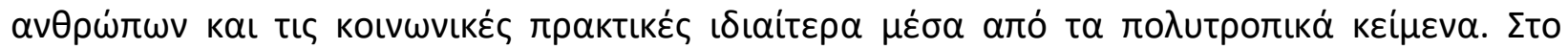

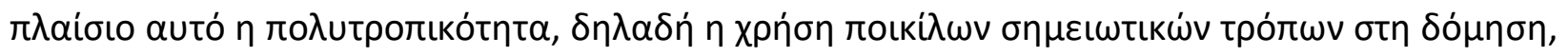

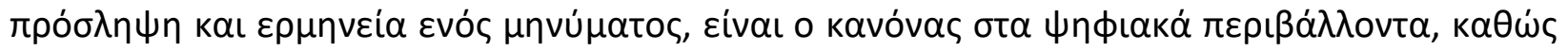

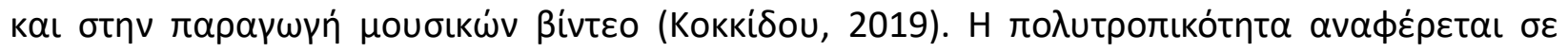

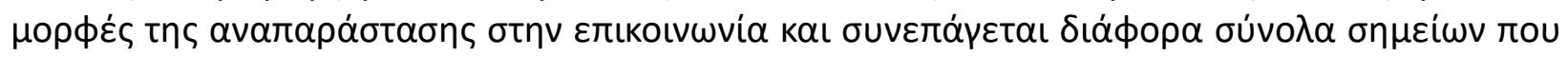

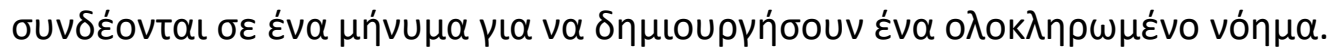

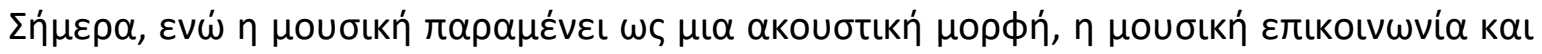

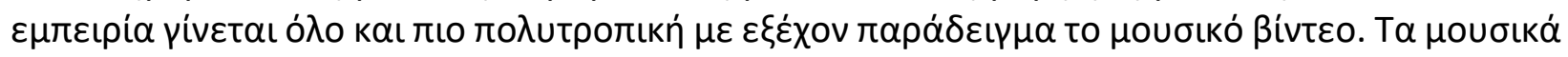

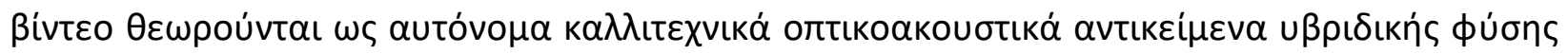


MULTILINGUAL ACADEMIC JOURNAL OF EDUCATION AND SOCIAL SCIENCES

Vol. 8 No. 1, 2020, E-ISSN: 2308-0876 @ 2020 KWP

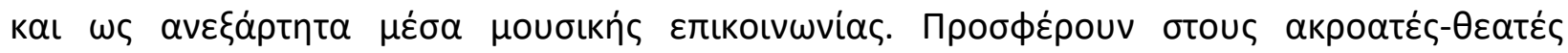

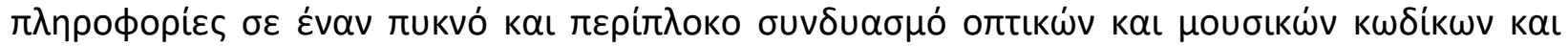

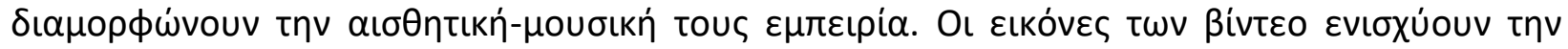

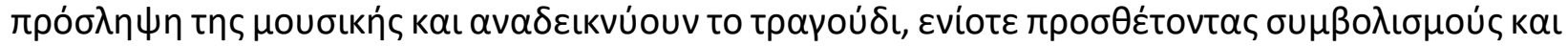

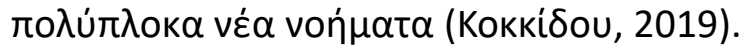

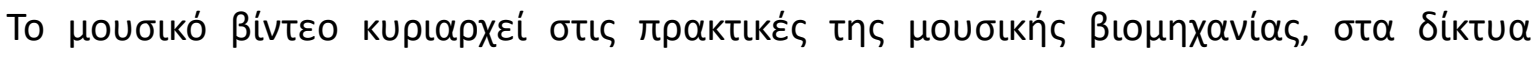

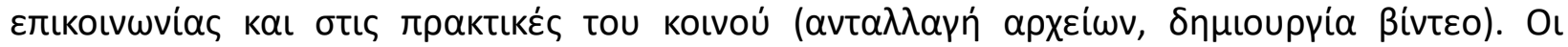

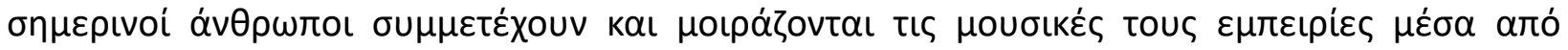

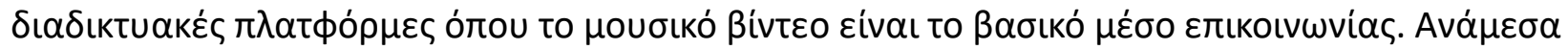

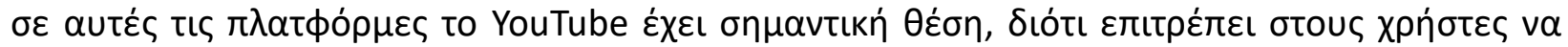

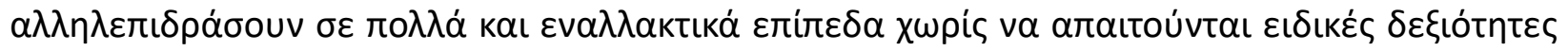

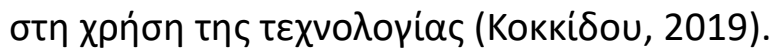

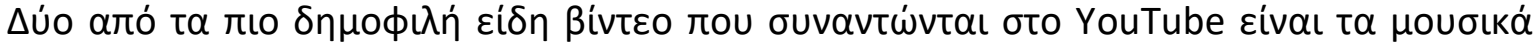

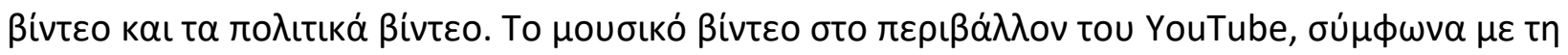

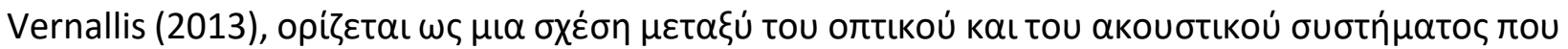

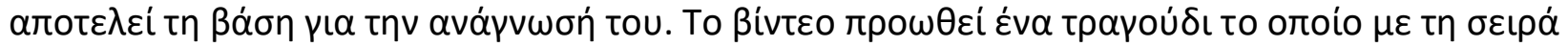

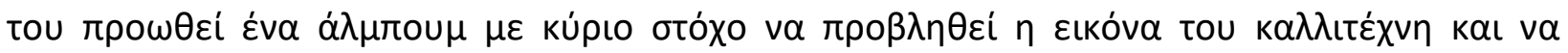

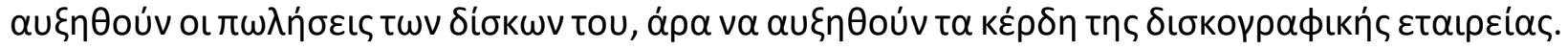

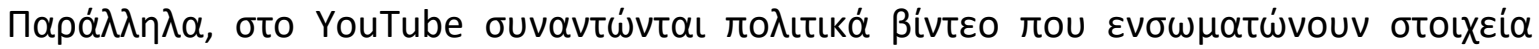

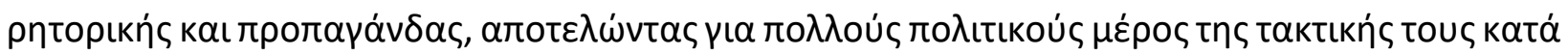

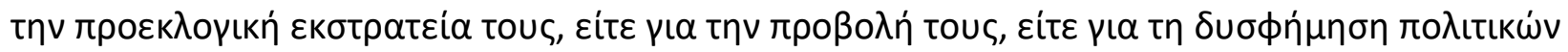

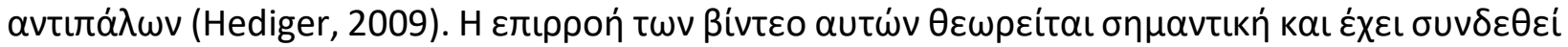

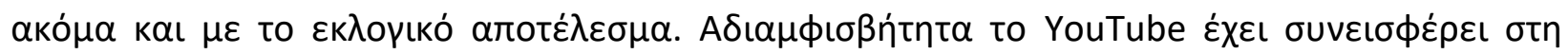

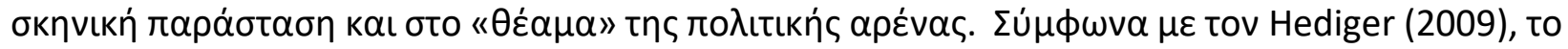

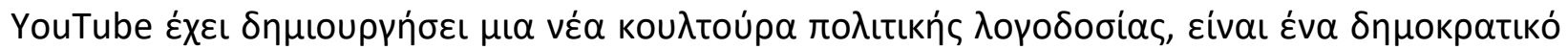

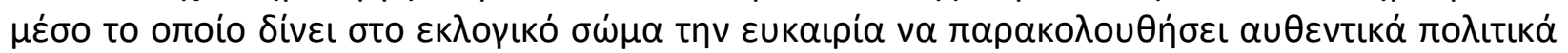

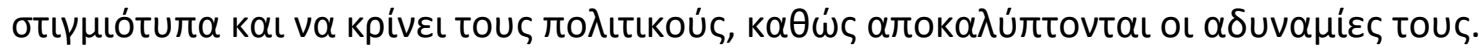

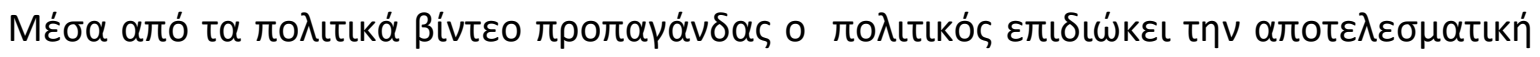

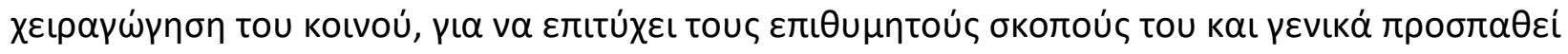

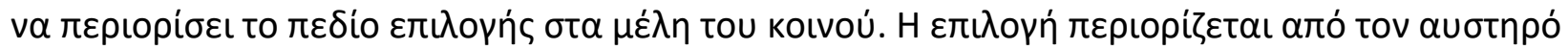

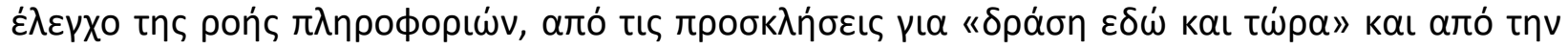

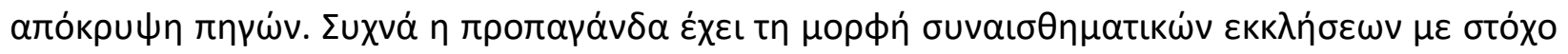

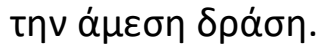

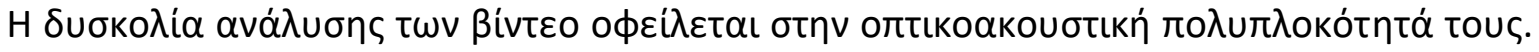

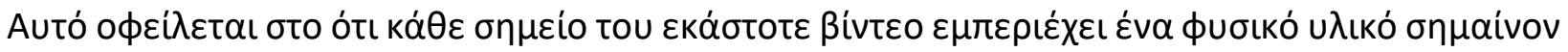

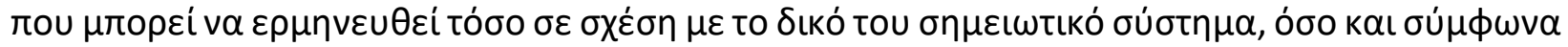

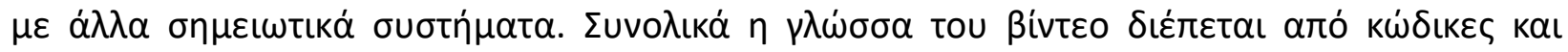

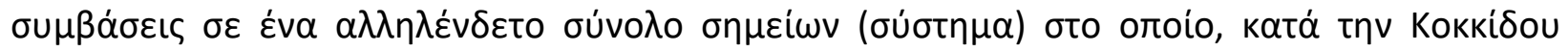

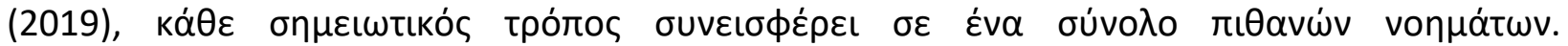

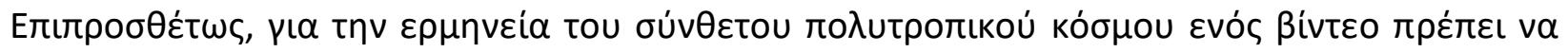

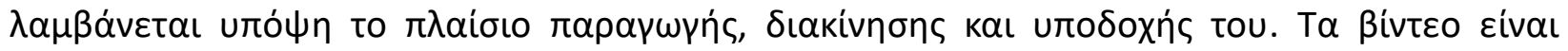

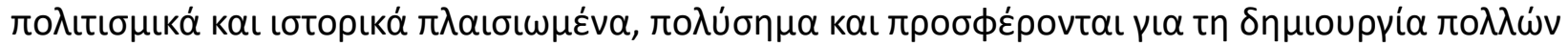

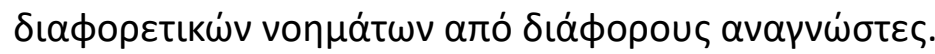


MULTILINGUAL ACADEMIC JOURNAL OF EDUCATION AND SOCIAL SCIENCES

Vol. 8 No. 1, 2020, E-ISSN: 2308-0876 @ 2020 KWP

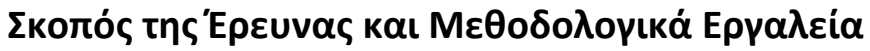

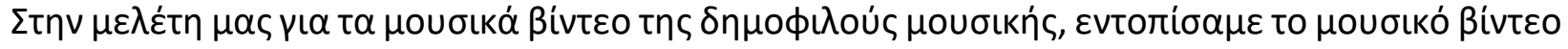

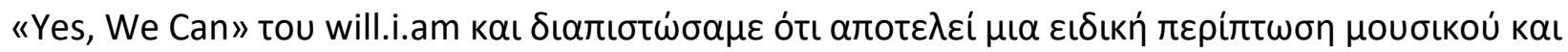

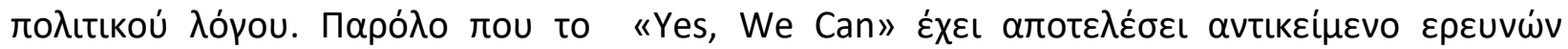

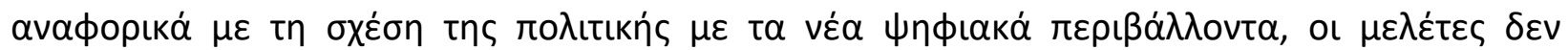

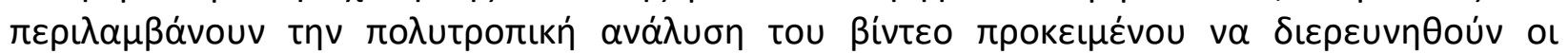

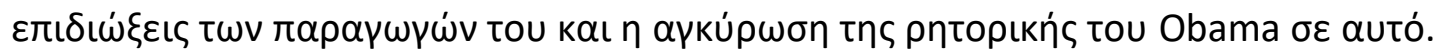

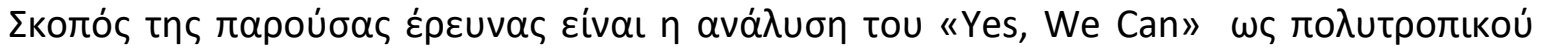

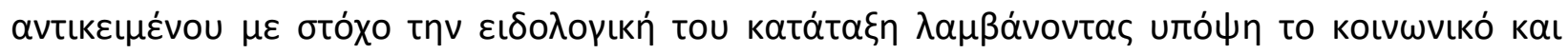

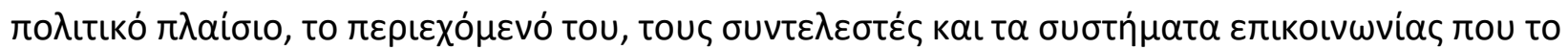

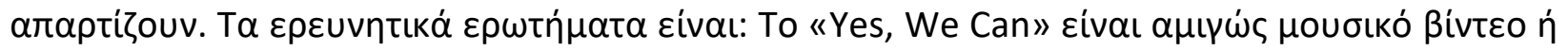

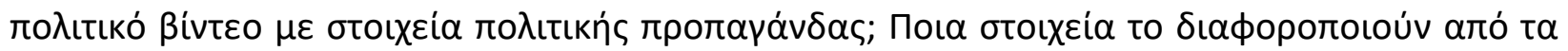

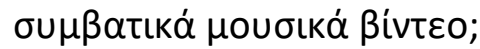

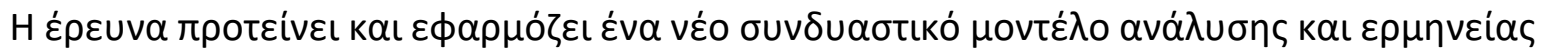

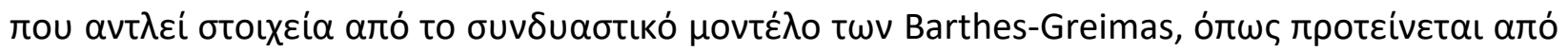

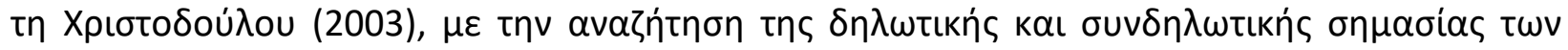

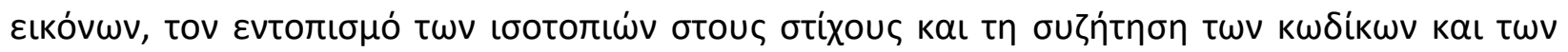

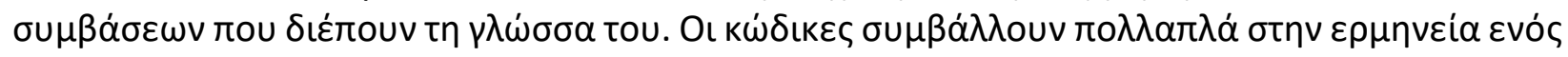

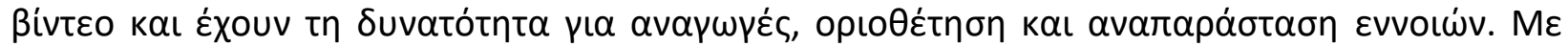

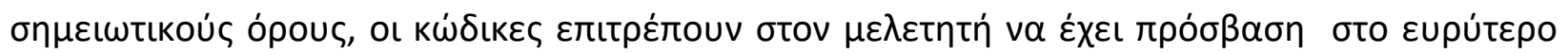

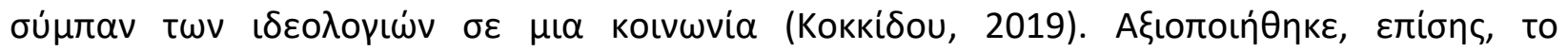
$\mu \varepsilon Ө$ $о \delta о \lambda о ү ı$ кó $\varepsilon \rho ү \alpha \lambda \varepsilon$ ío tou Cook (1998); Khalid, Islam \& Ahmed (2019); Alzgool (2019)

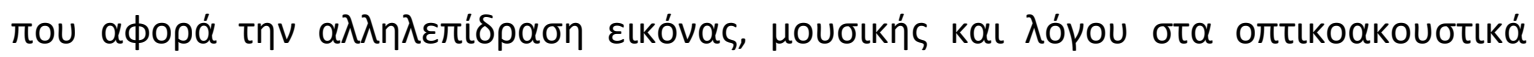

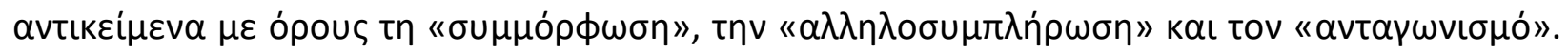

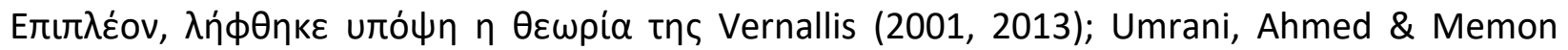

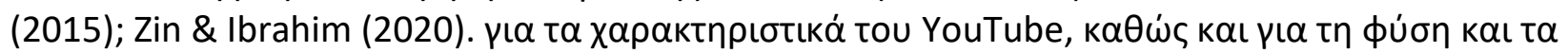

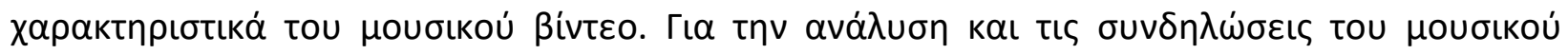

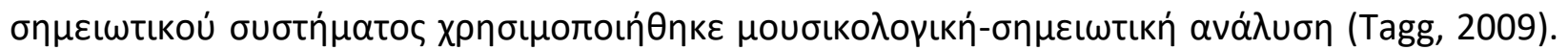

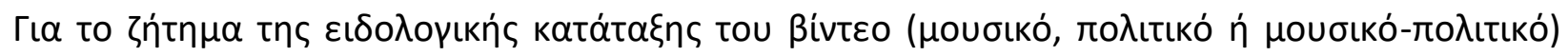

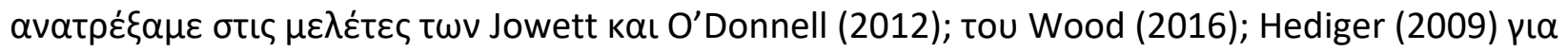

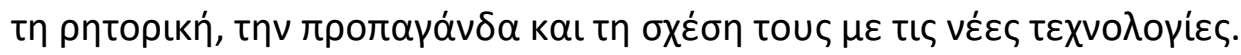

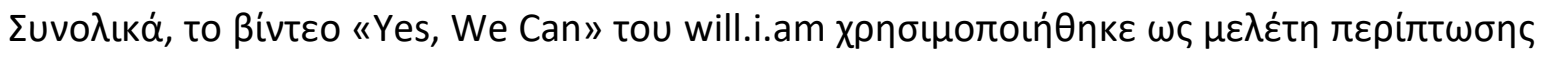

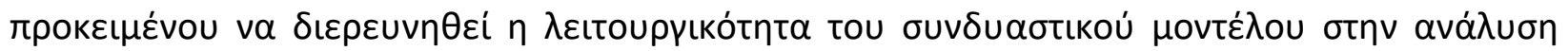

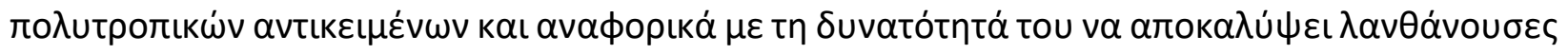

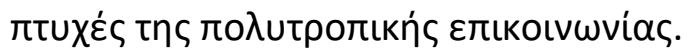

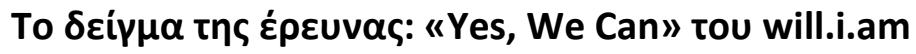

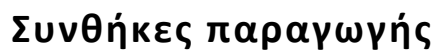

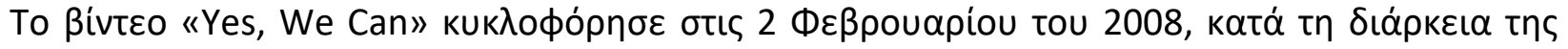

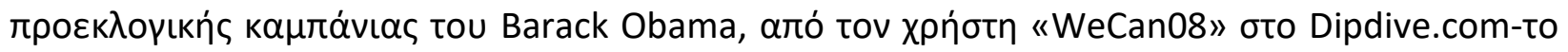

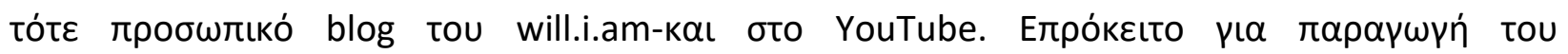

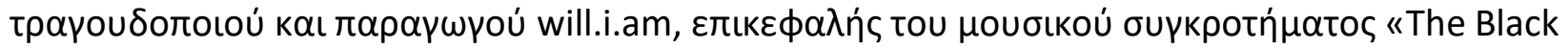

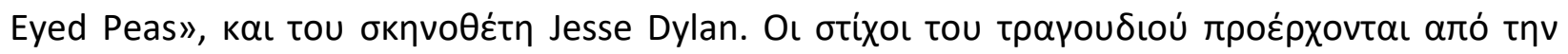

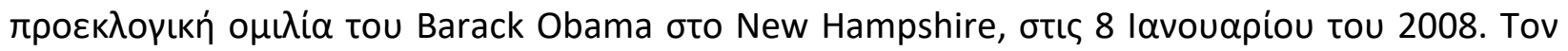


MULTILINGUAL ACADEMIC JOURNAL OF EDUCATION AND SOCIAL SCIENCES

Vol. 8 No. 1, 2020, E-ISSN: 2308-0876 @ 2020 KWP

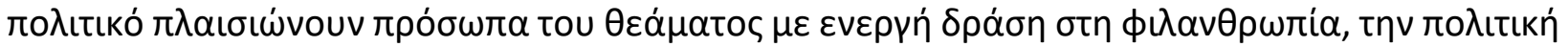

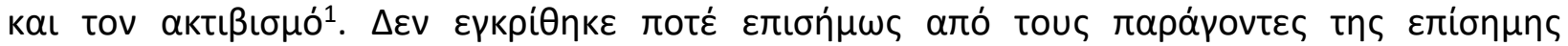

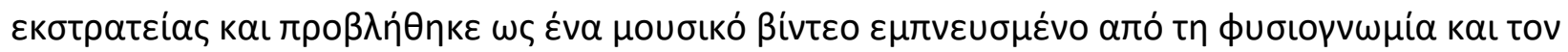

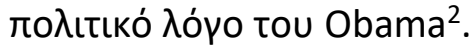

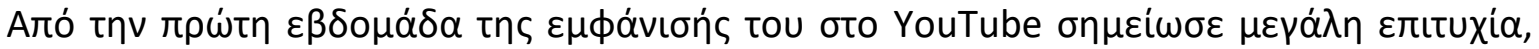

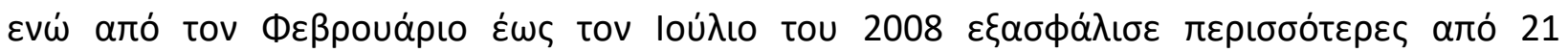

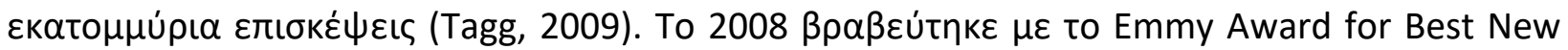
Approaches in Daytime Entertainment.

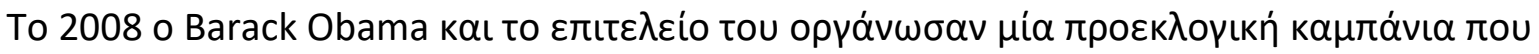

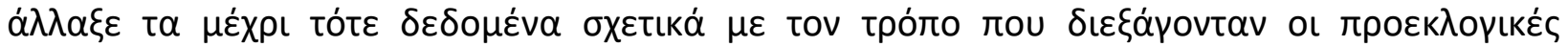

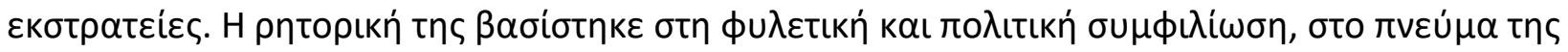

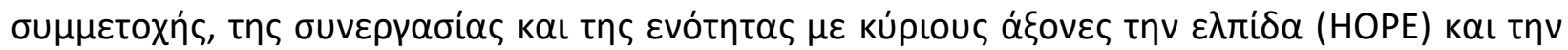

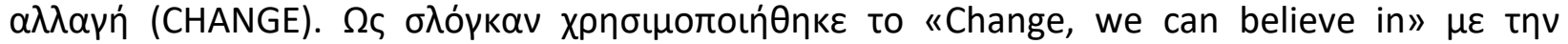

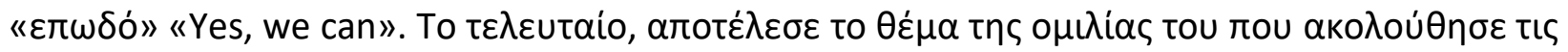

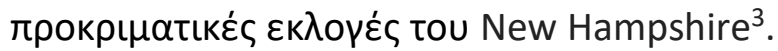

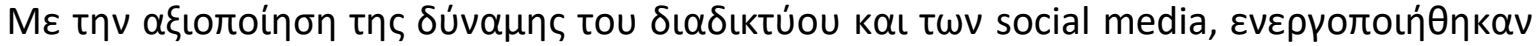

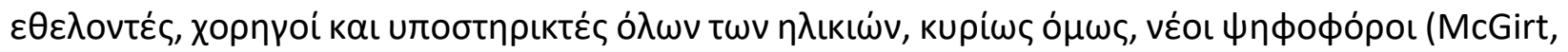

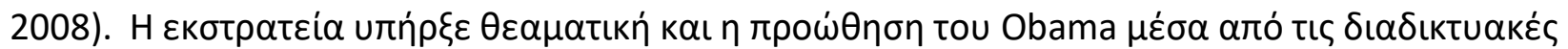

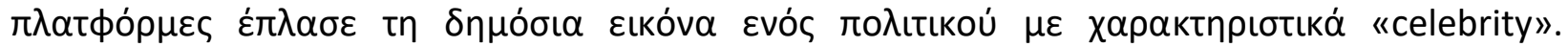

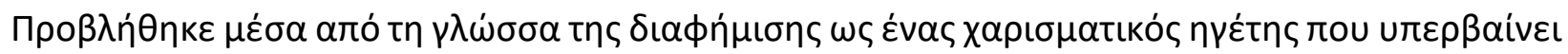

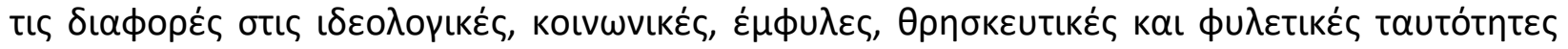
(Redmond, 2010).

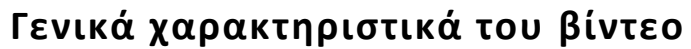

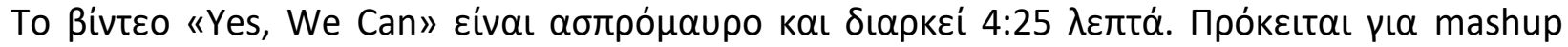

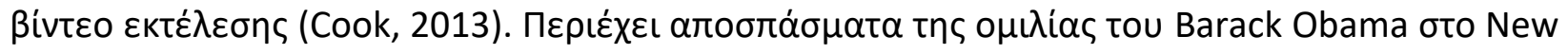

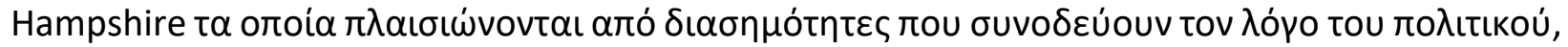

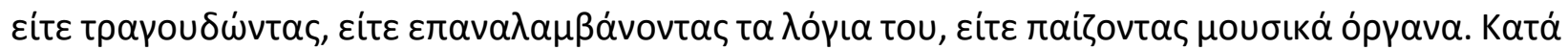

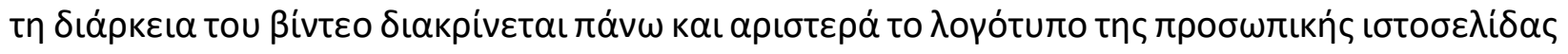

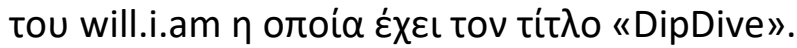

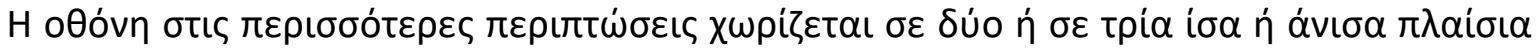

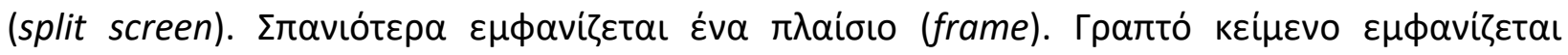

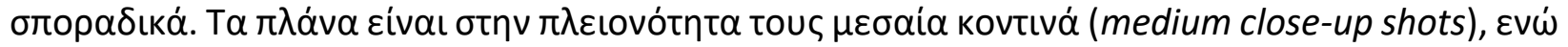

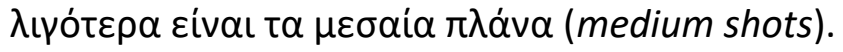

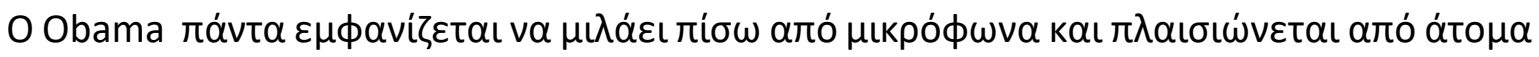

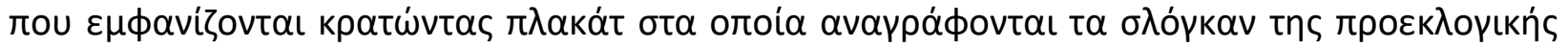

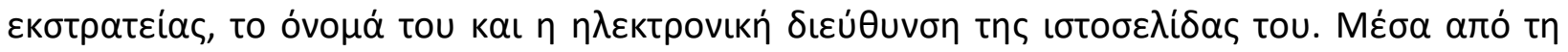

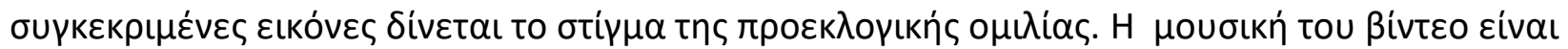

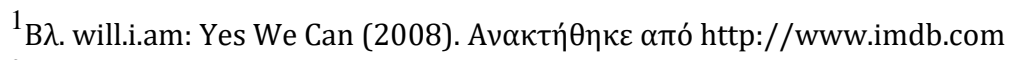

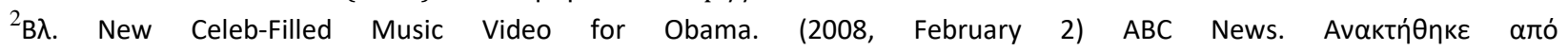
http://abcnews.go.com/Politics/story?id=4231523\&page=1

${ }^{3} \mathrm{~B} \lambda$. Obama, B. (2008, January 8). New Hampshire Primary Concession Speech. Retreived from http://www.americanrhetoric.com/mp3clipsXE/barackobama/barackobamannewhampshireconcessionARXE.mp3
} 
MULTILINGUAL ACADEMIC JOURNAL OF EDUCATION AND SOCIAL SCIENCES

Vol. 8 No. 1, 2020, E-ISSN: 2308-0876 @ 2020 KWP

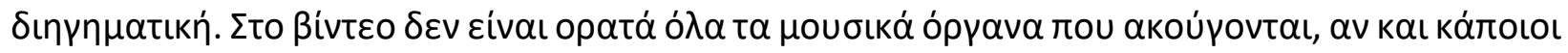

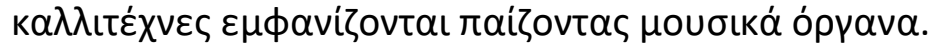

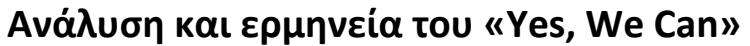

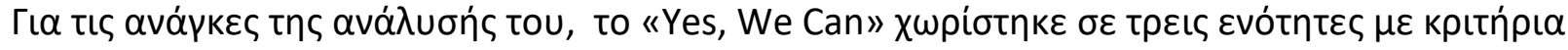

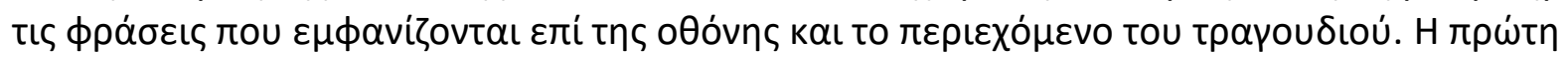

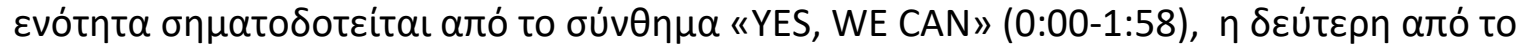

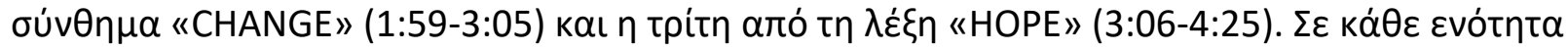

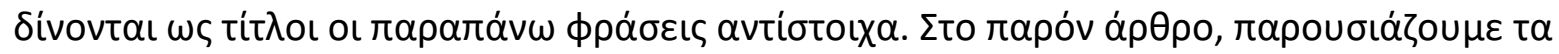

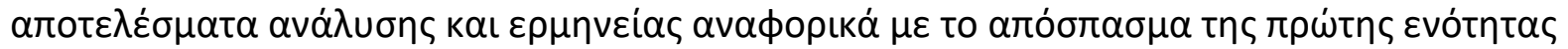

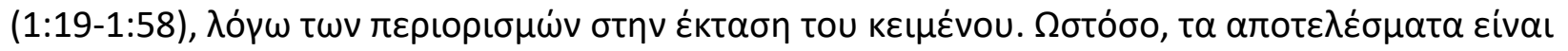

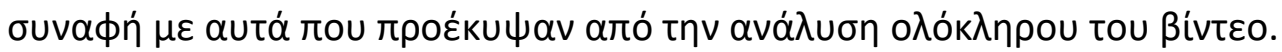

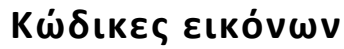

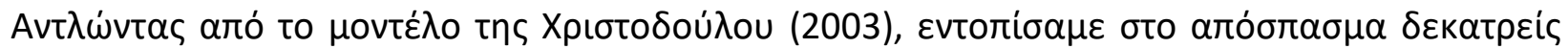

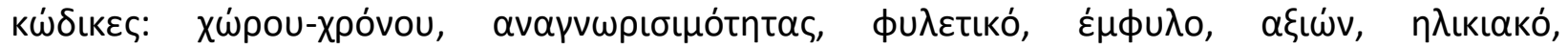

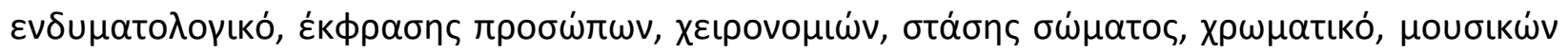

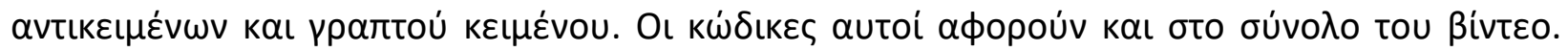

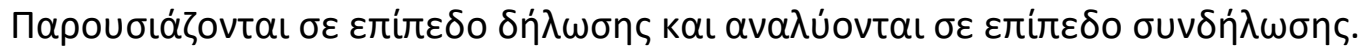

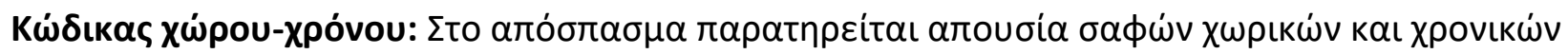

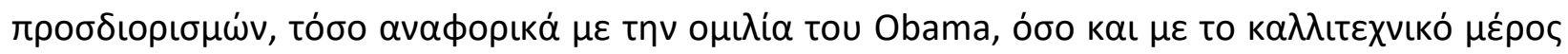

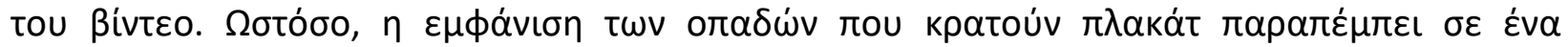

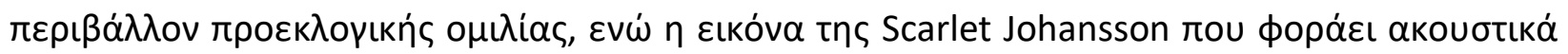

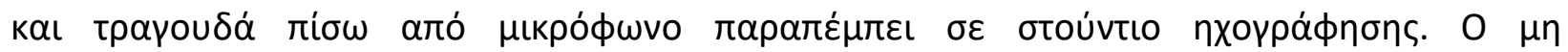

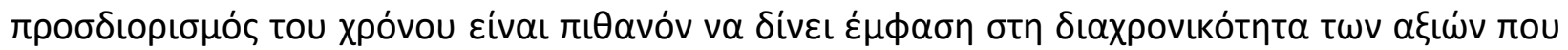

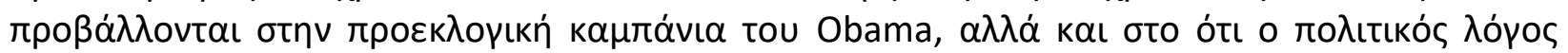

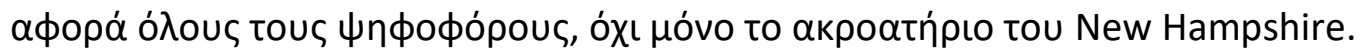

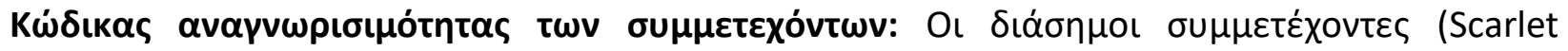
Johansson, John Legend, Nicol Scherzinger, Kate Walsh, will.i.am, Amber Valletta, к.á.) $\delta \varepsilon v$

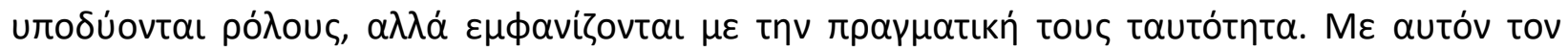

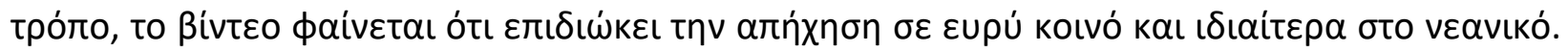

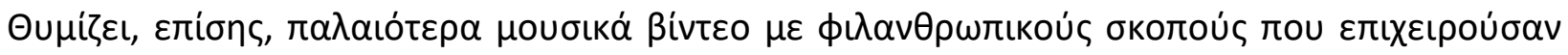

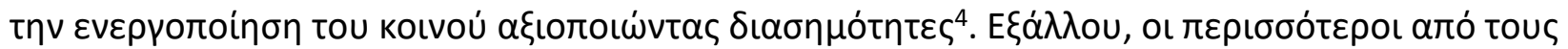

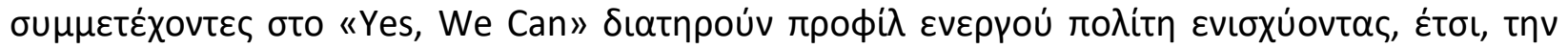

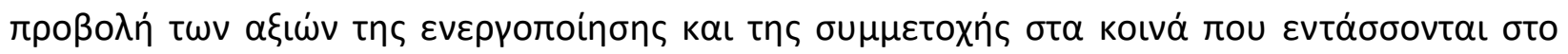

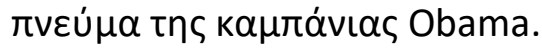

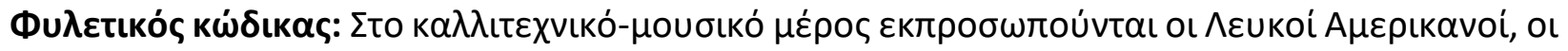

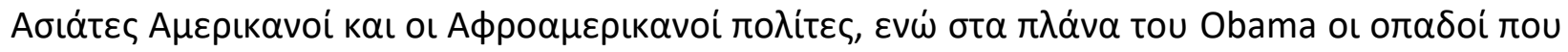

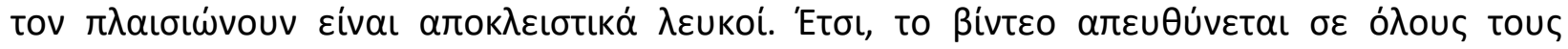

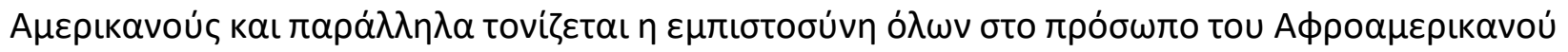

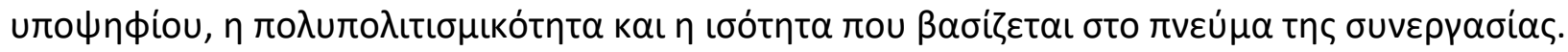

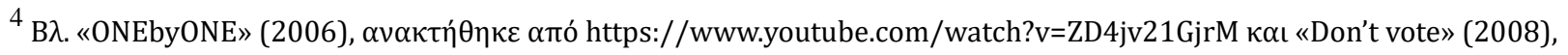
$\alpha v \alpha \kappa \tau \eta \dot{\theta \eta \kappa \varepsilon ~} \alpha \pi$ th https://www.youtube.com/watch?v=Bo_iExUsQWE
} 
MULTILINGUAL ACADEMIC JOURNAL OF EDUCATION AND SOCIAL SCIENCES

Vol. 8 No. 1, 2020, E-ISSN: 2308-0876 @ 2020 KWP

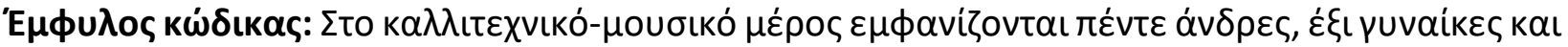

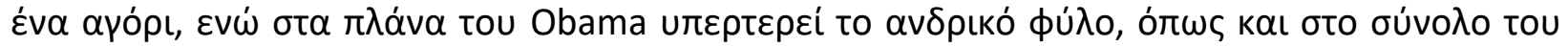

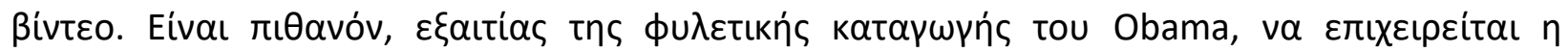

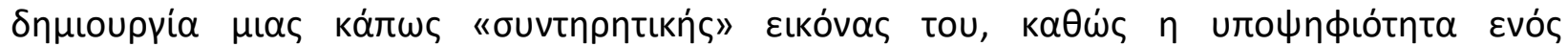

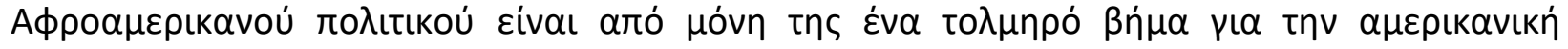

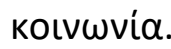

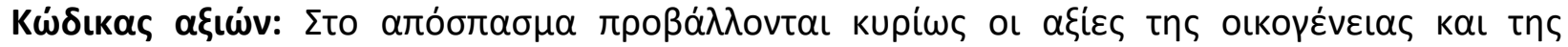

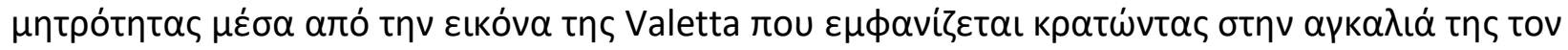

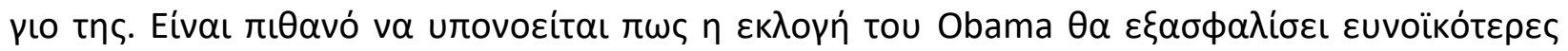

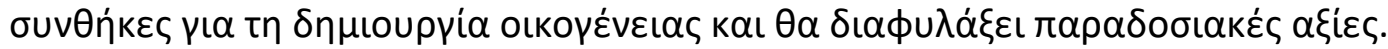

Н

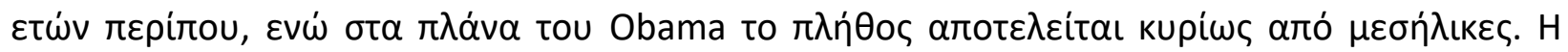

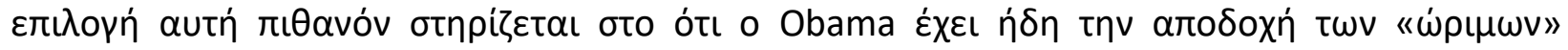

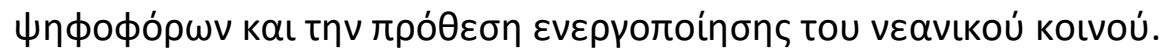

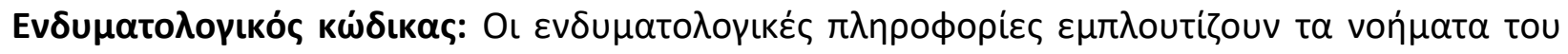

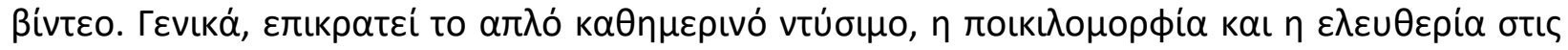

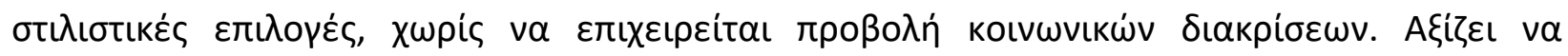

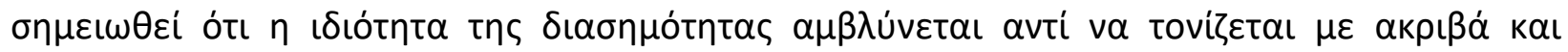

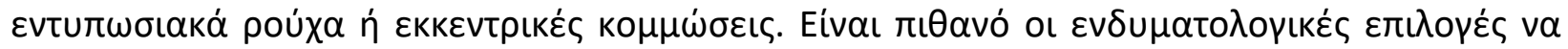

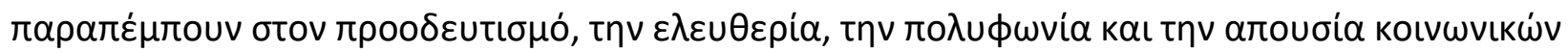

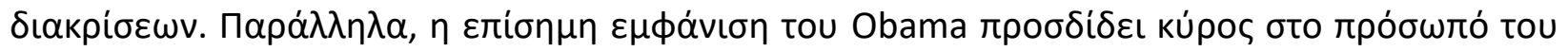

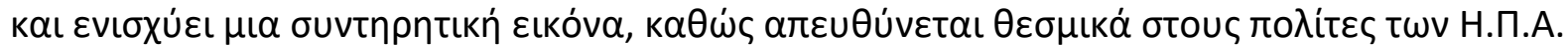

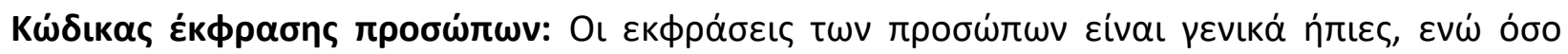

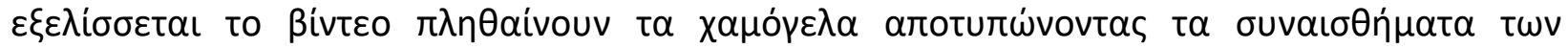

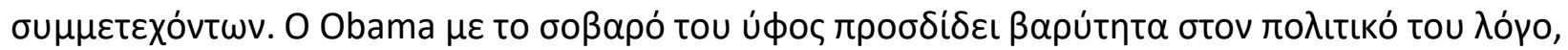

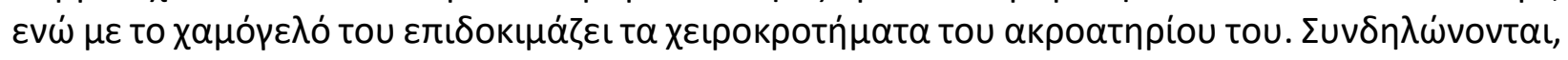

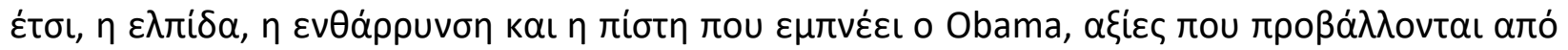

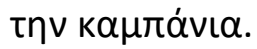

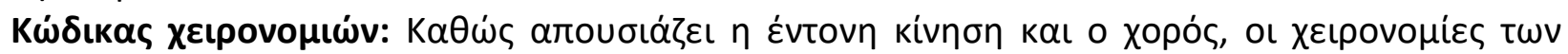

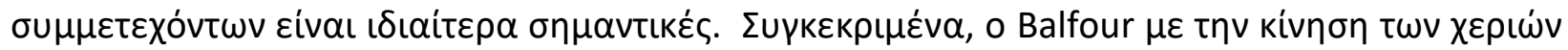

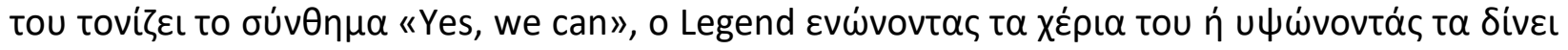

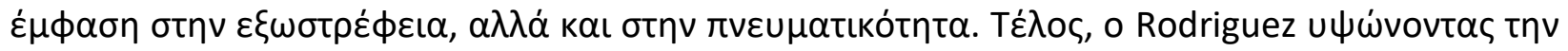

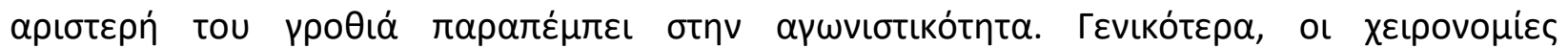

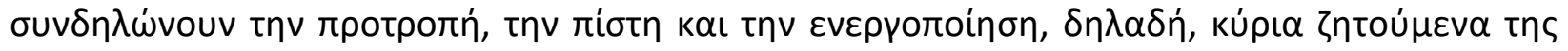

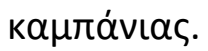

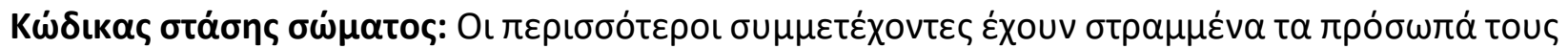

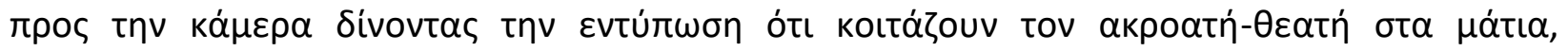

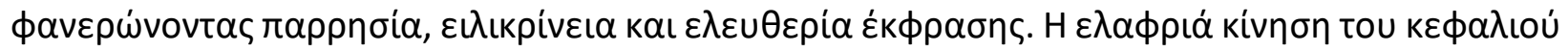

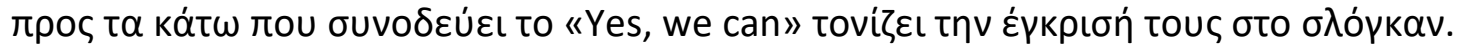

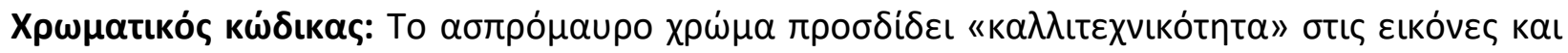

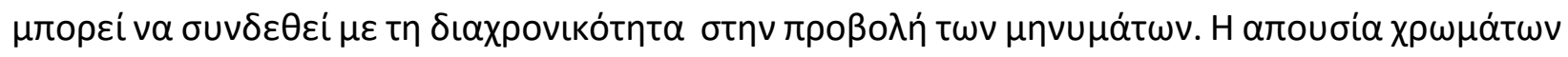

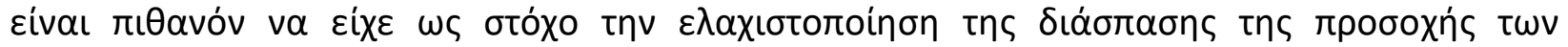

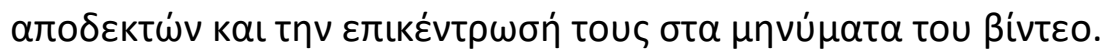


MULTILINGUAL ACADEMIC JOURNAL OF EDUCATION AND SOCIAL SCIENCES

Vol. 8 No. 1, 2020, E-ISSN: 2308-0876 @ 2020 KWP

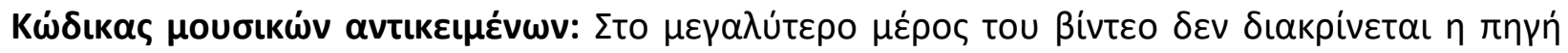

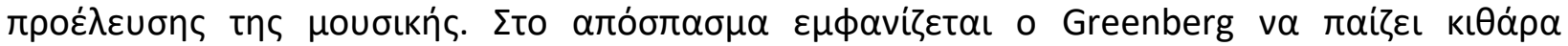

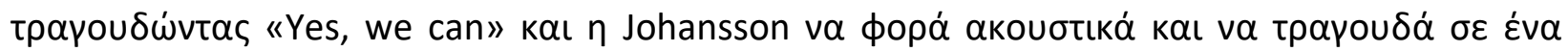

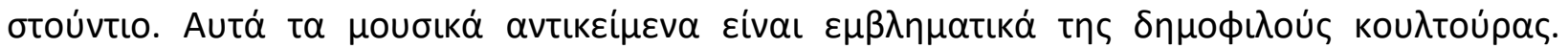

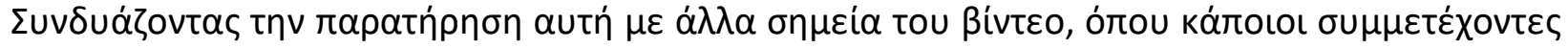

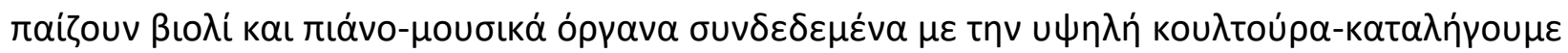

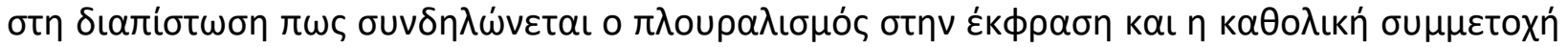

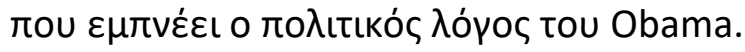

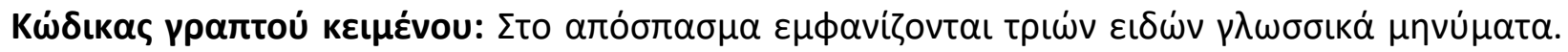

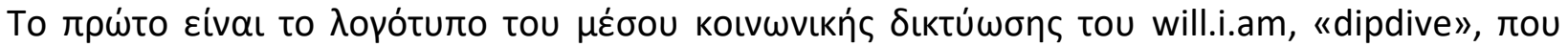

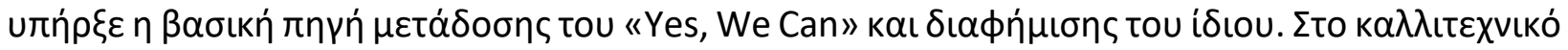

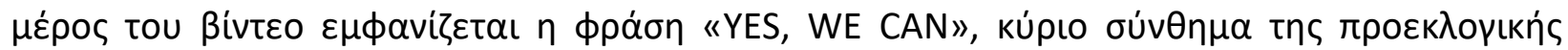

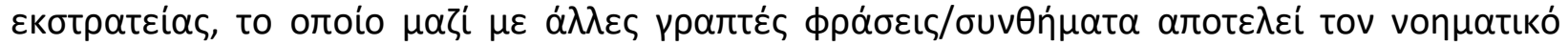

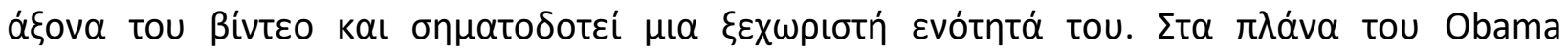

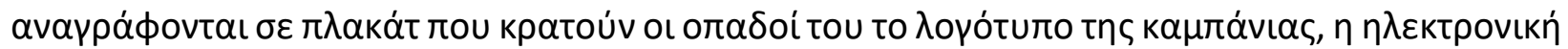

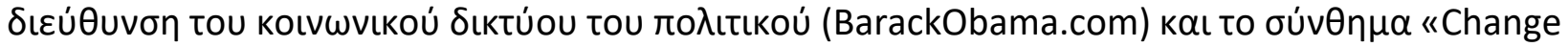

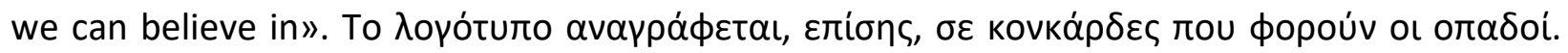

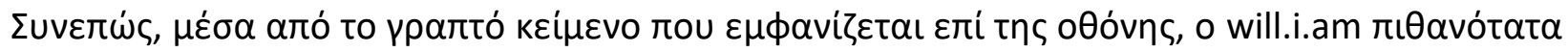

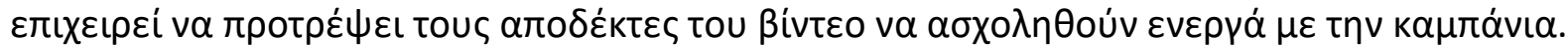

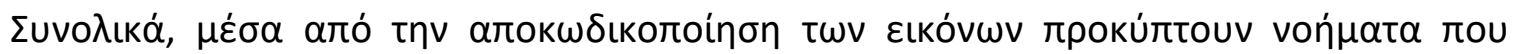

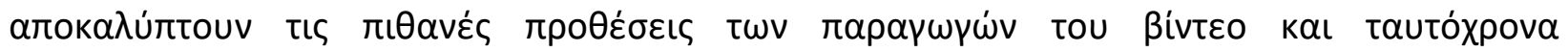

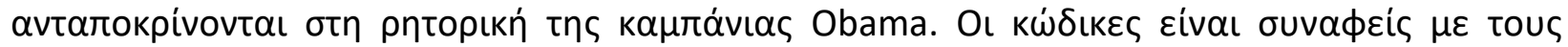

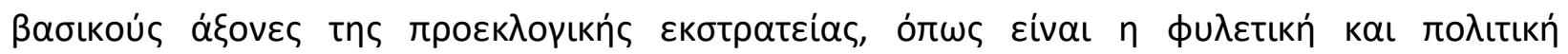

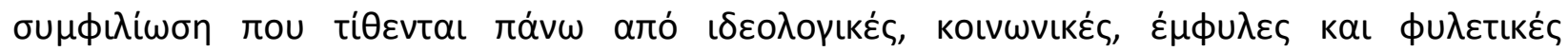

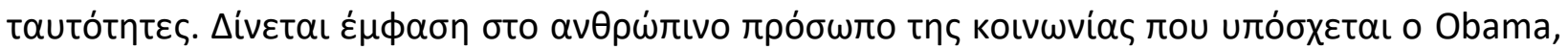

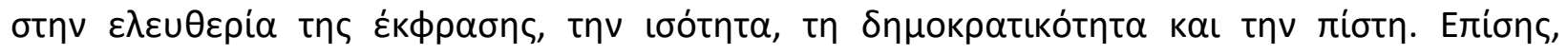

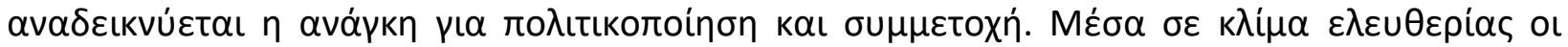

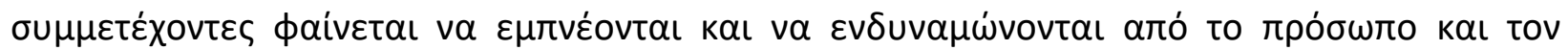

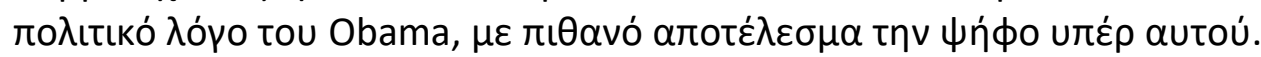

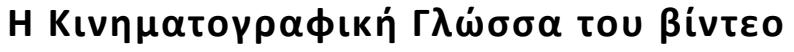

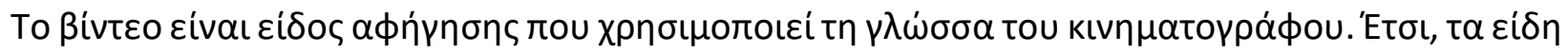

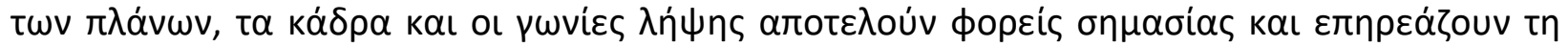

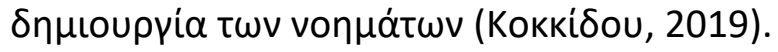

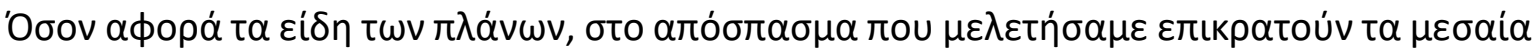

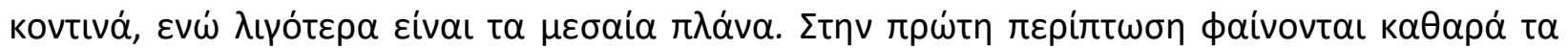

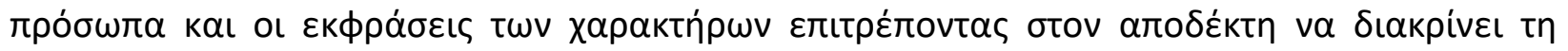

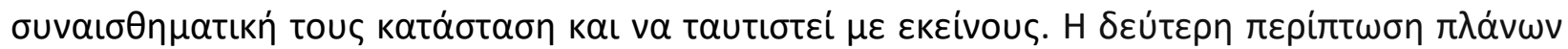

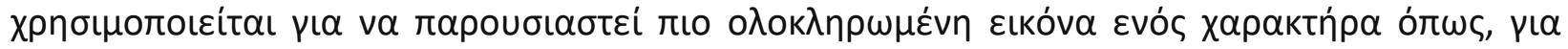

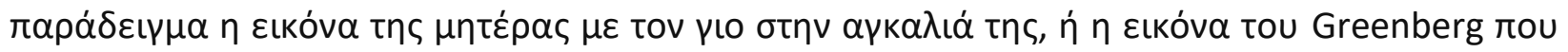

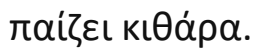

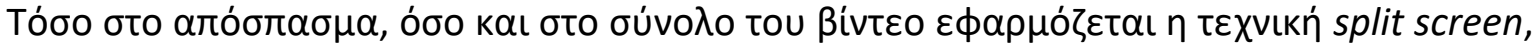

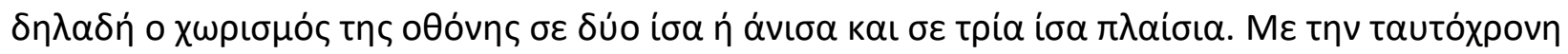

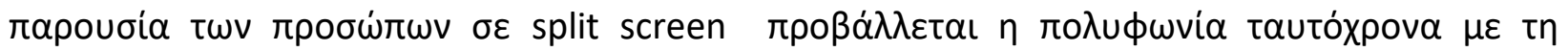


MULTILINGUAL ACADEMIC JOURNAL OF EDUCATION AND SOCIAL SCIENCES

Vol. 8 No. 1, 2020, E-ISSN: 2308-0876 @ 2020 KWP

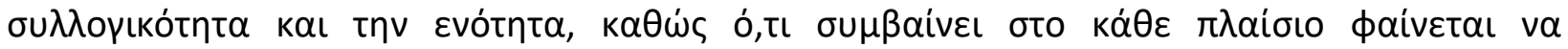

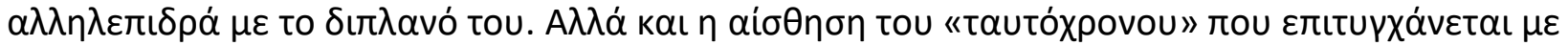

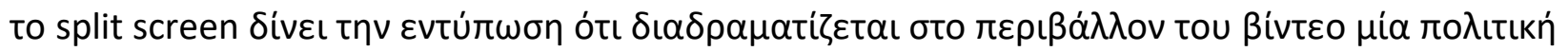

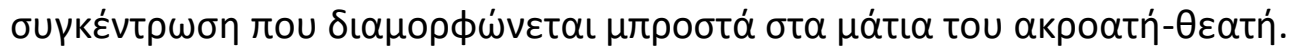

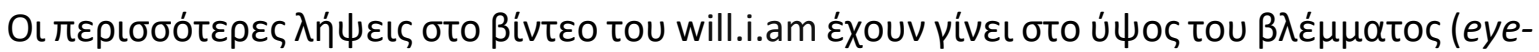

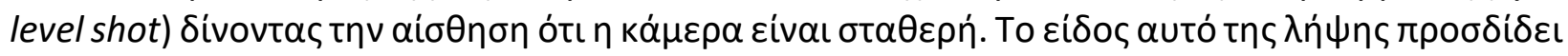

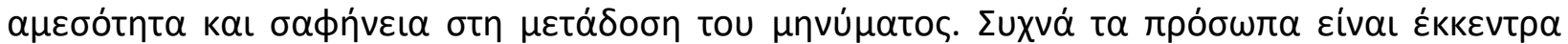

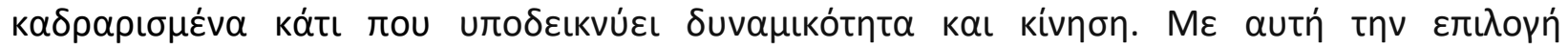

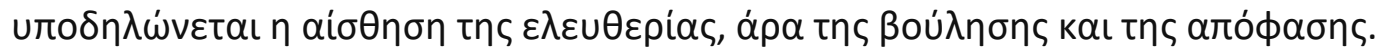

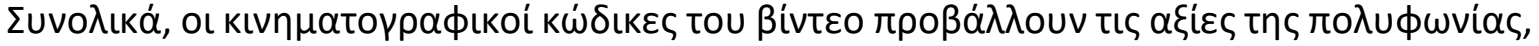

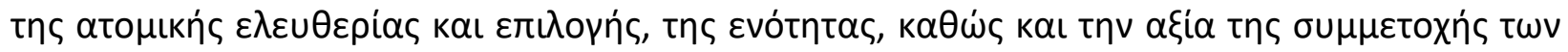

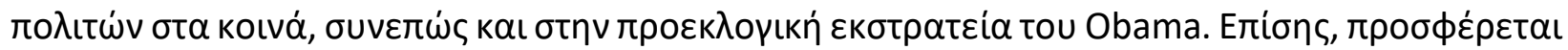

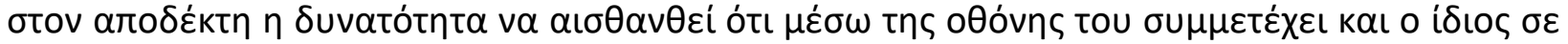

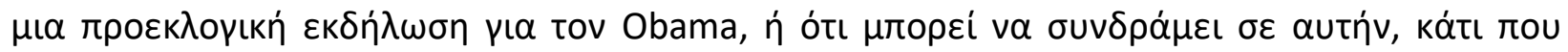

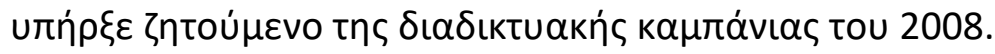

\section{Avóduon $\sigma \tau i \dot{\chi} \chi \omega v$}

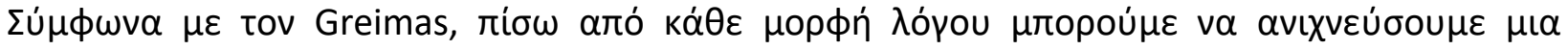

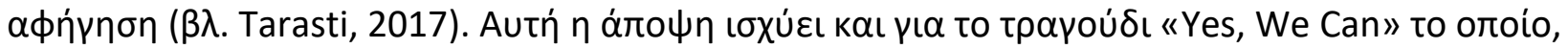

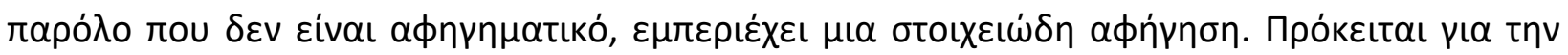

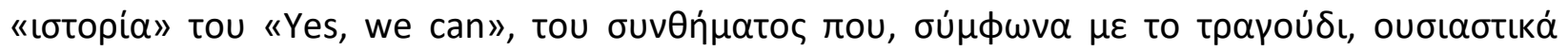

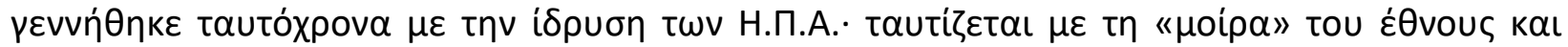

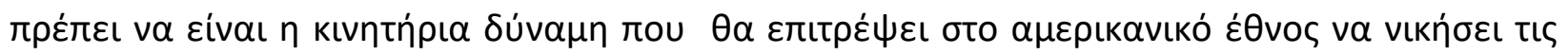

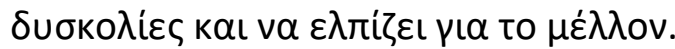

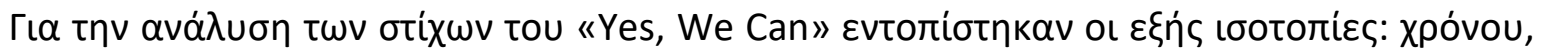

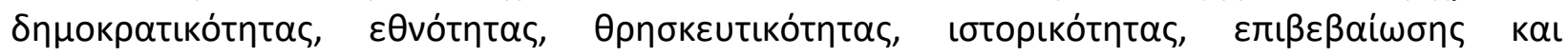

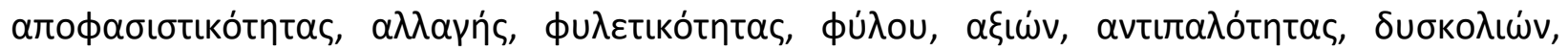

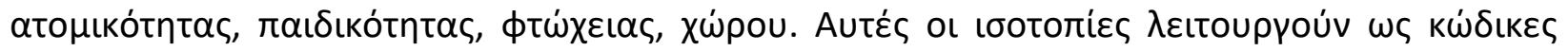

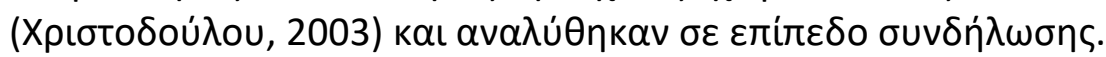

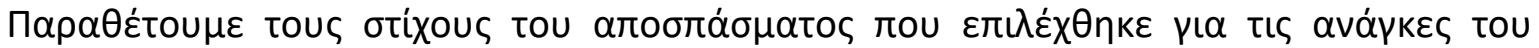
á $\rho \rho \rho u$ :

Yes, we can to opportunity and prosperity.

Yes, we can to opportunity and prosperity.

Yes, we can heal this nation. Heal this nation.

Yes, we can repair this world. Repair this world.

Yes, we can. Yes, we can. Yes, we can. Qen, annu yecholim. Yes, we can. Si, podemos. Sí, se puede.

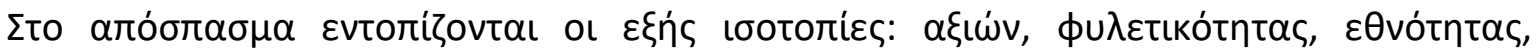

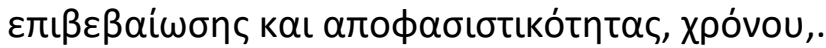

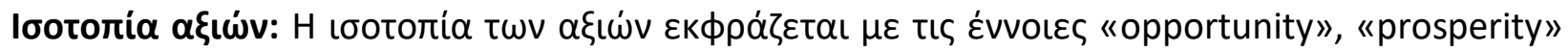

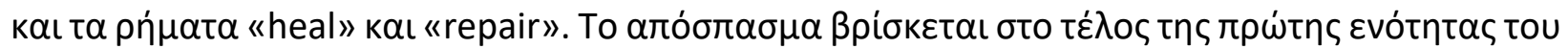

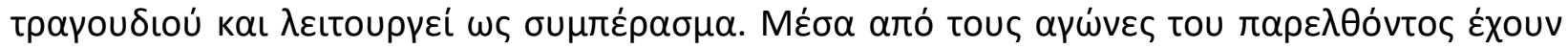

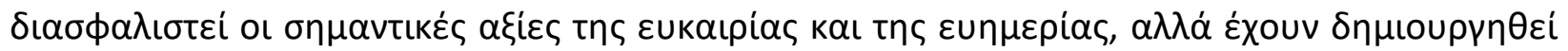

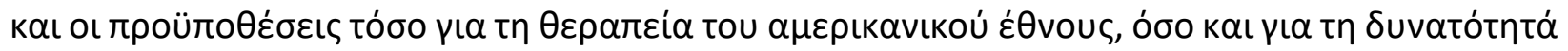


MULTILINGUAL ACADEMIC JOURNAL OF EDUCATION AND SOCIAL SCIENCES

Vol. 8 No. 1, 2020, E-ISSN: 2308-0876 @ 2020 KWP

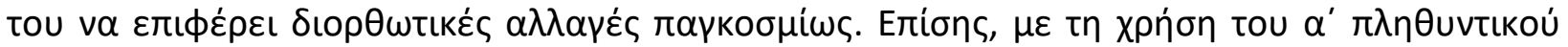

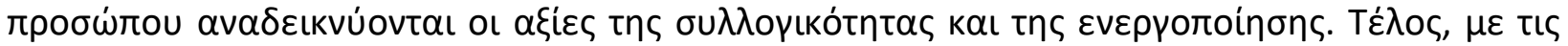

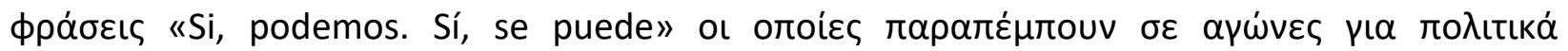

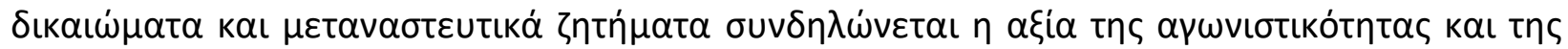
เoótntac.

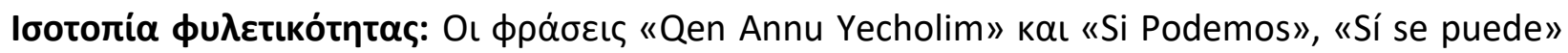

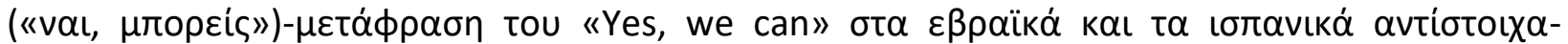

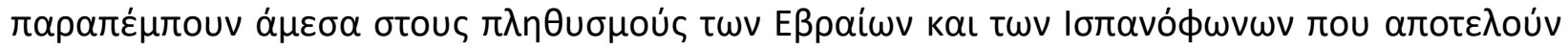

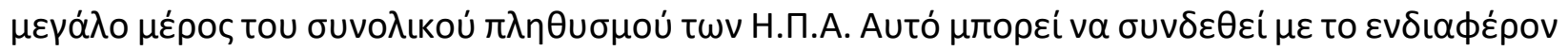

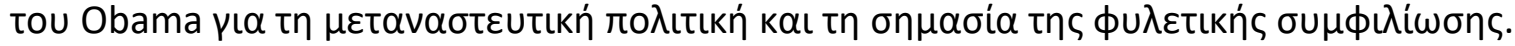

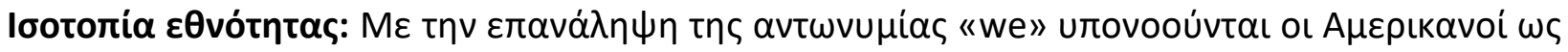

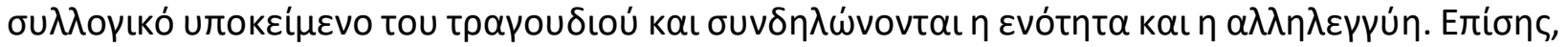

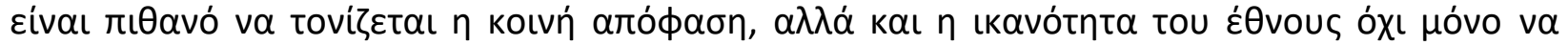

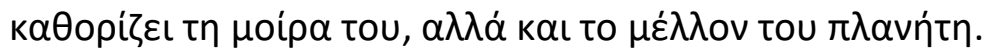

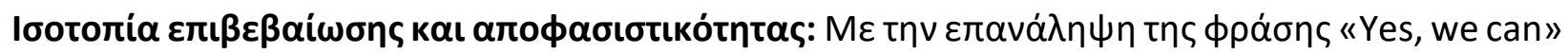

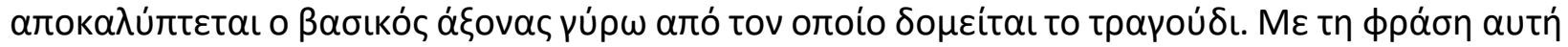

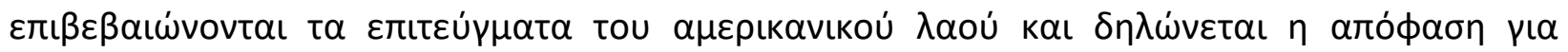

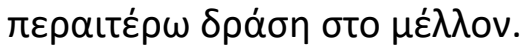

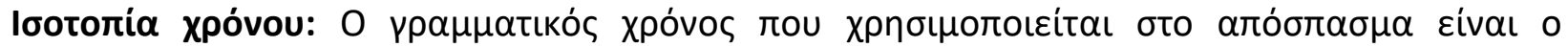

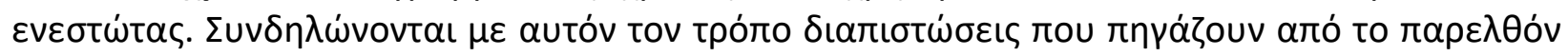

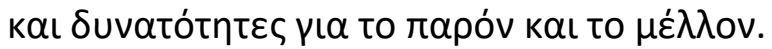

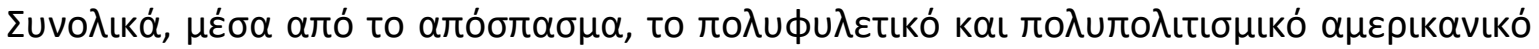

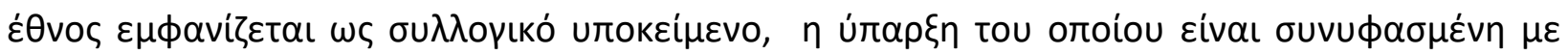

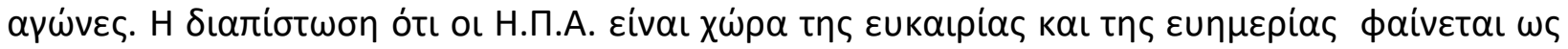

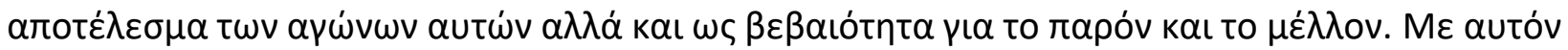

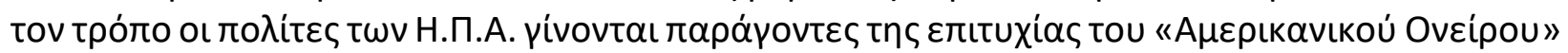

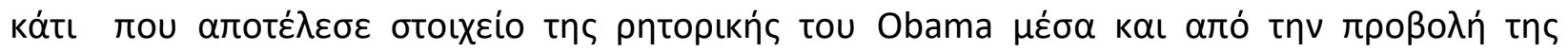

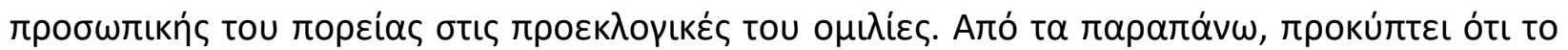

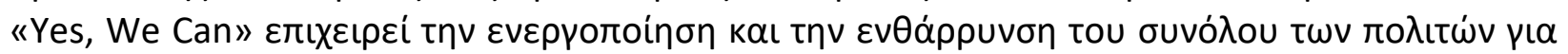

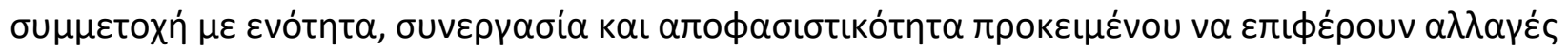

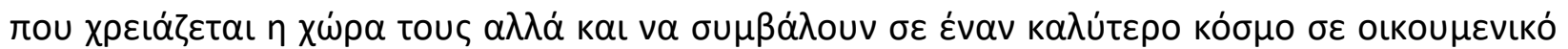
$\varepsilon \pi i ́ r \varepsilon \delta o$.

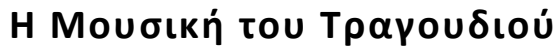

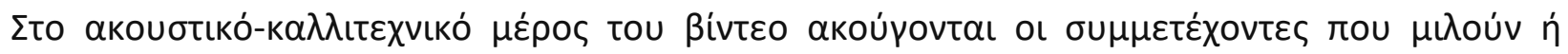

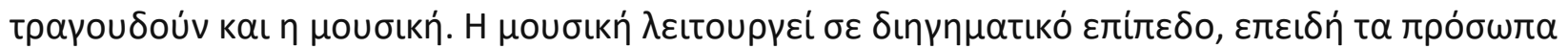

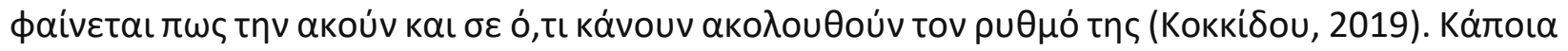

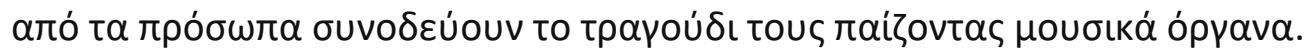

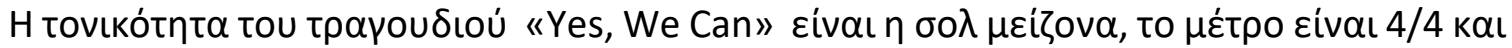

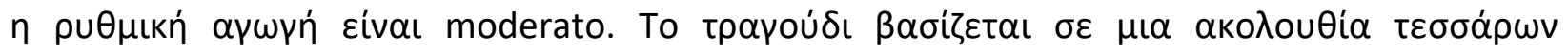

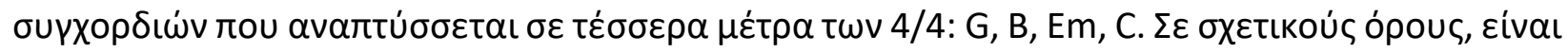

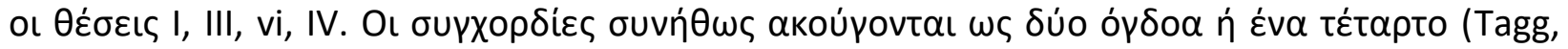

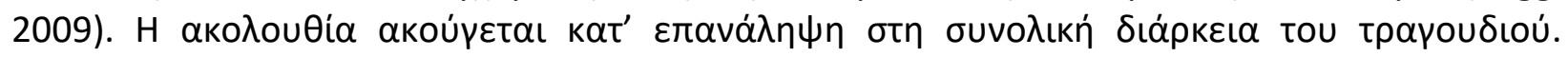


MULTILINGUAL ACADEMIC JOURNAL OF EDUCATION AND SOCIAL SCIENCES

Vol. 8 No. 1, 2020, E-ISSN: 2308-0876 @ 2020 KWP

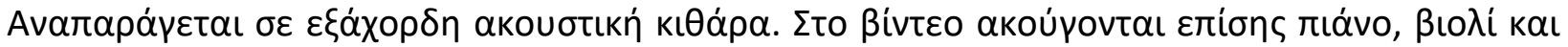

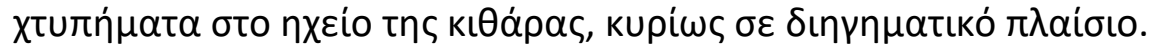

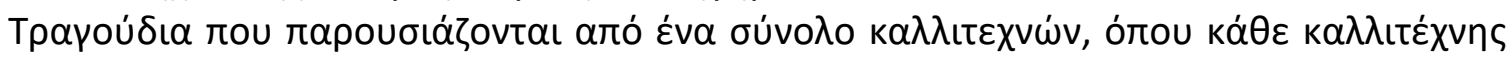

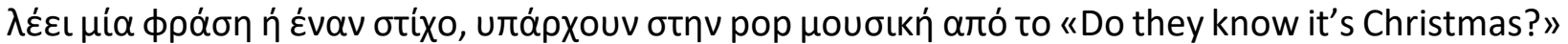

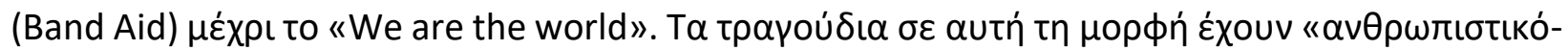

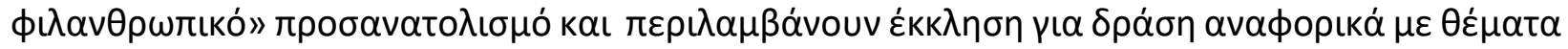

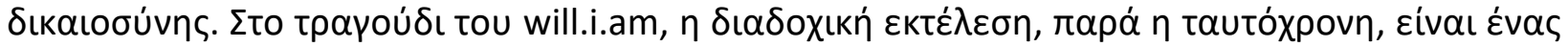

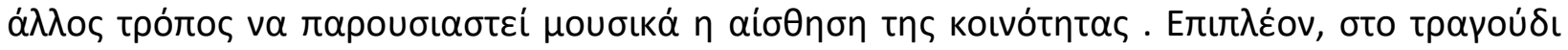

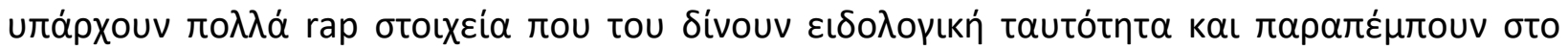

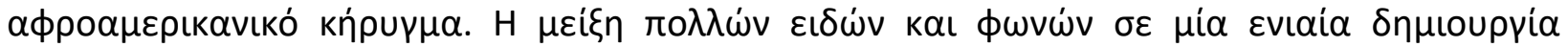

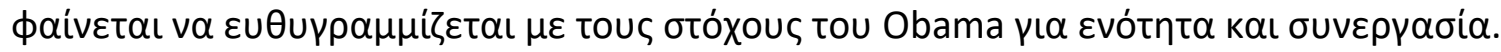

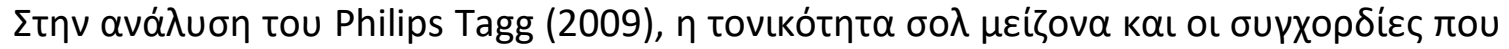

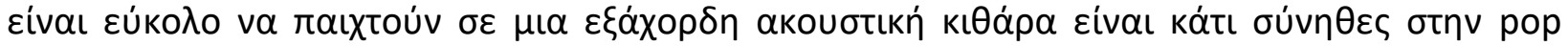

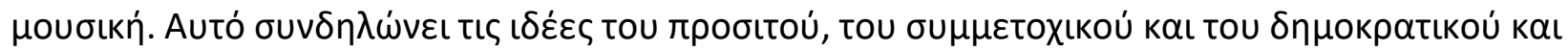

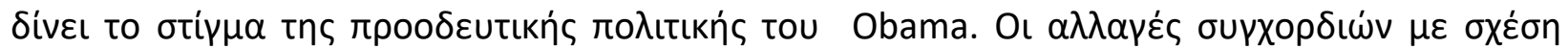

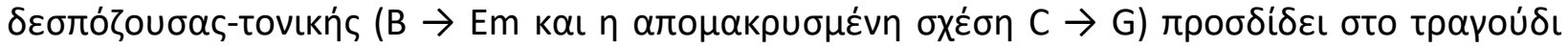

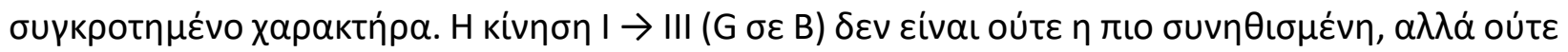

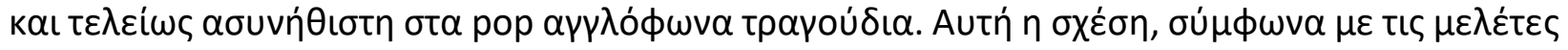

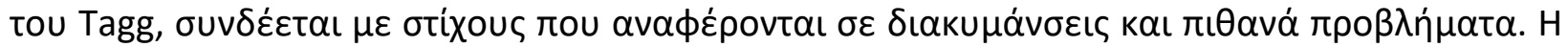

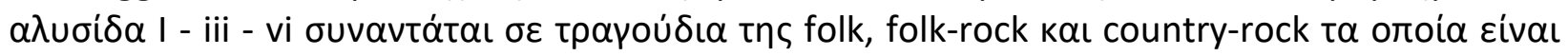

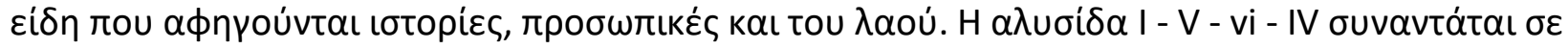

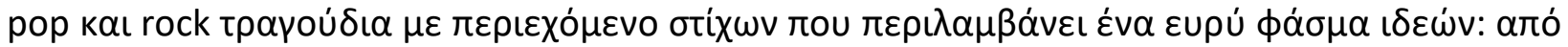

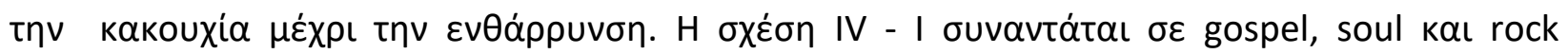

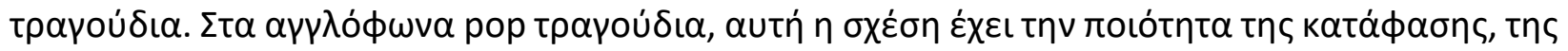

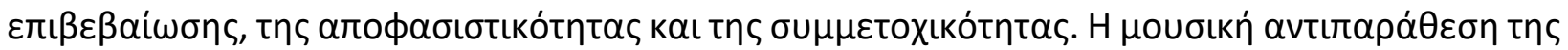

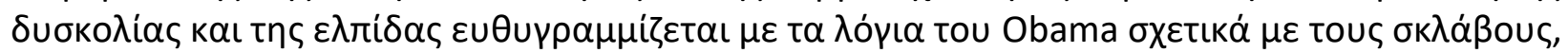

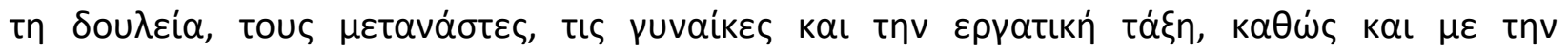

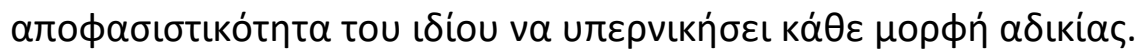

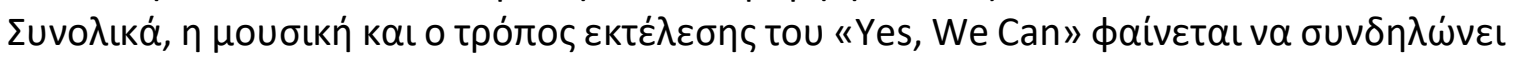

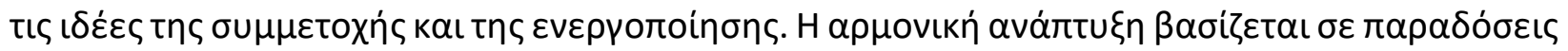

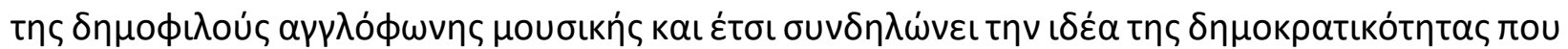

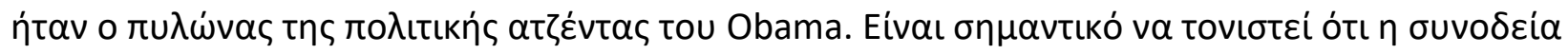

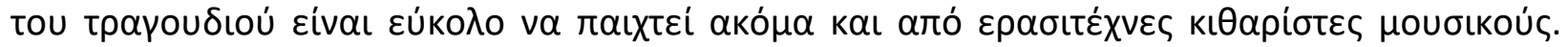

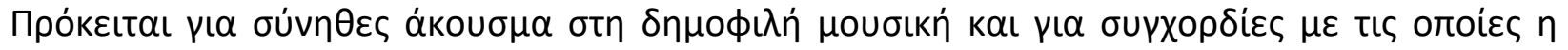

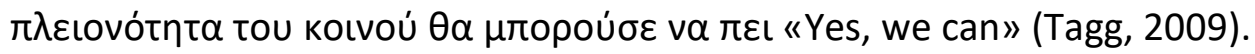

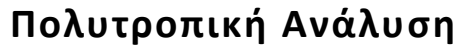

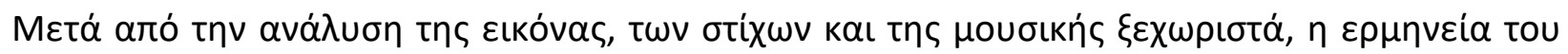

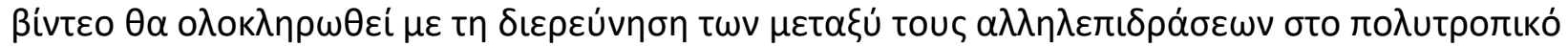

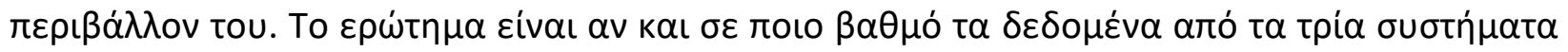

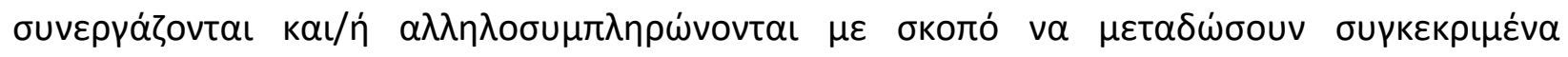
voń $\mu \alpha \tau \alpha$.

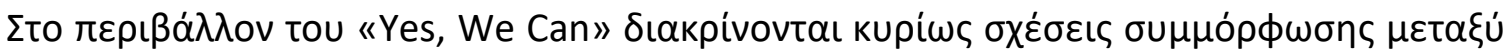

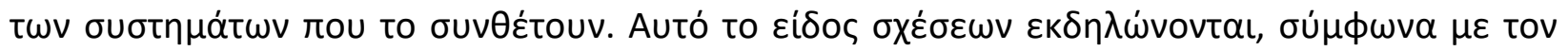


MULTILINGUAL ACADEMIC JOURNAL OF EDUCATION AND SOCIAL SCIENCES

Vol. 8 No. 1, 2020, E-ISSN: 2308-0876 @ 2020 KWP

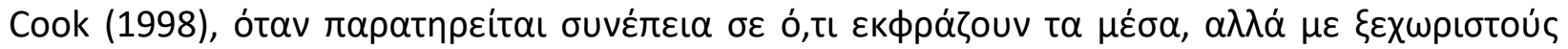

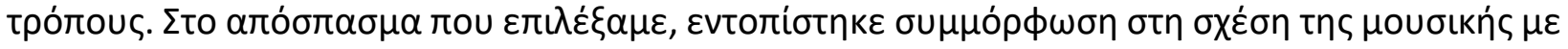

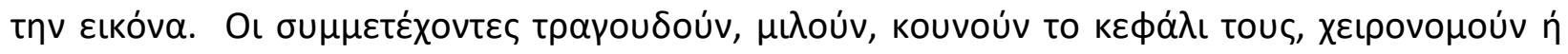

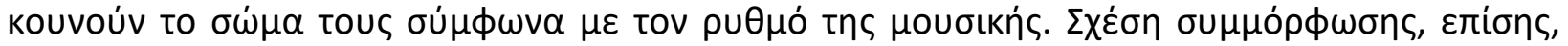

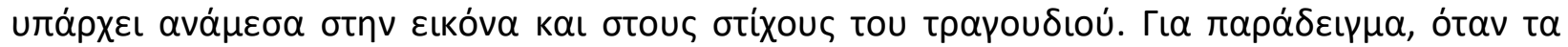

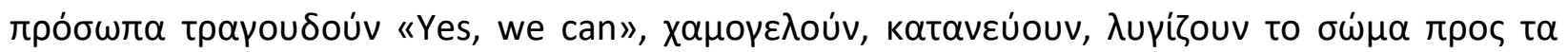

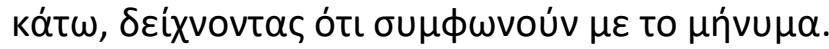

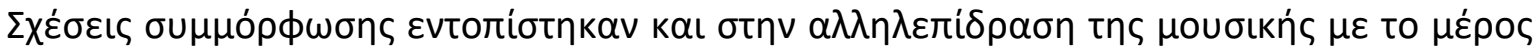

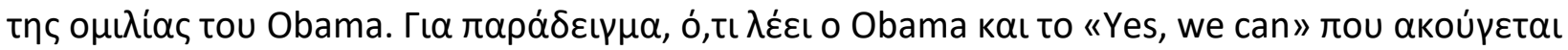

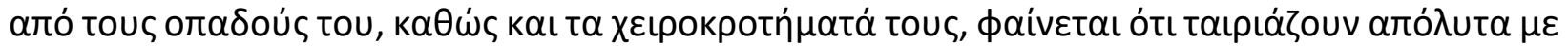

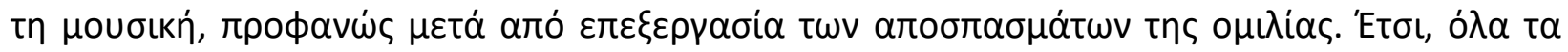

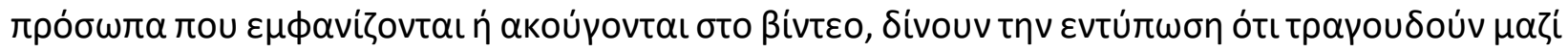

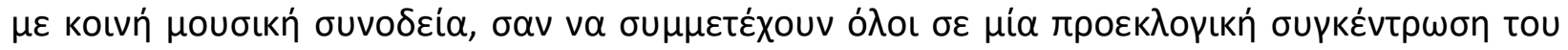

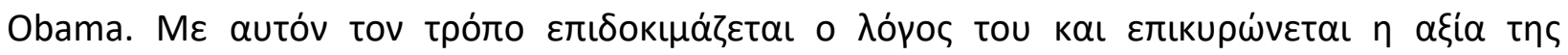

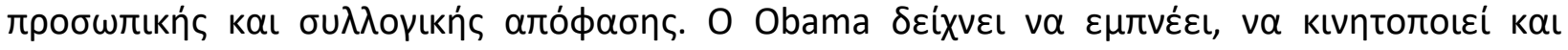

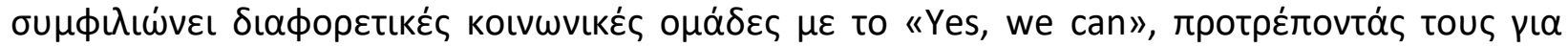

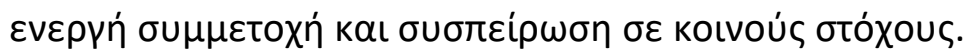

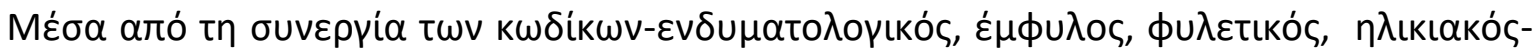

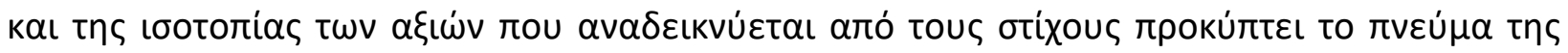

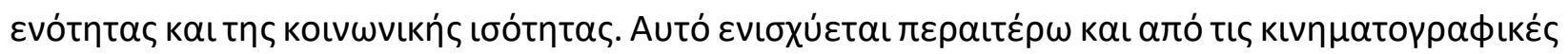

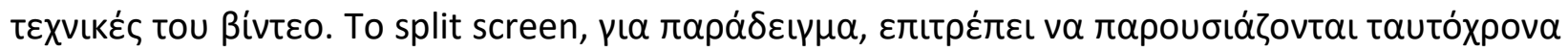

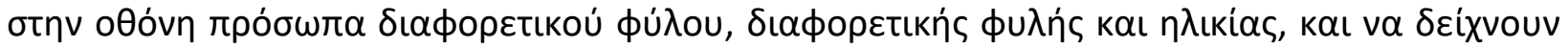

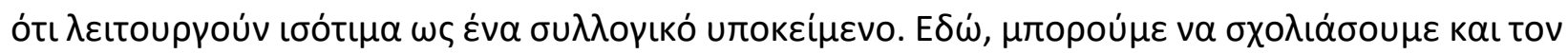

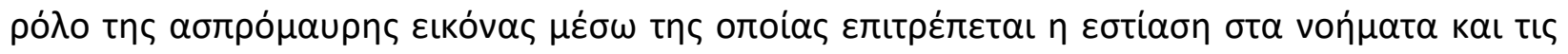

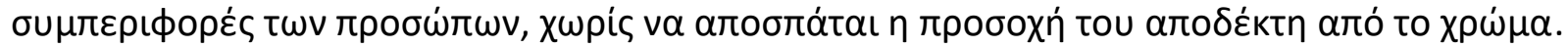

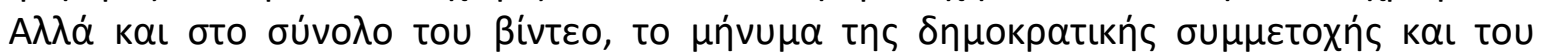

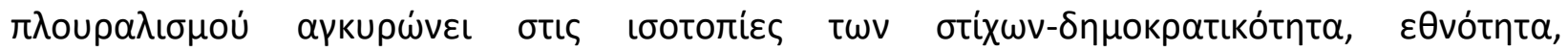

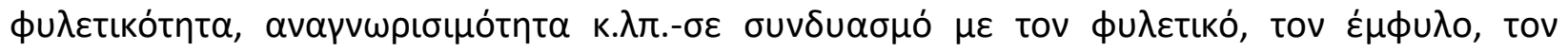

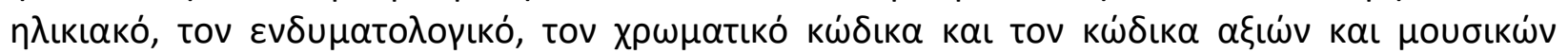

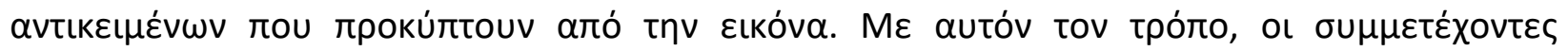

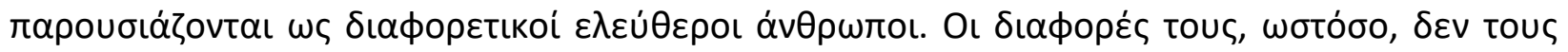

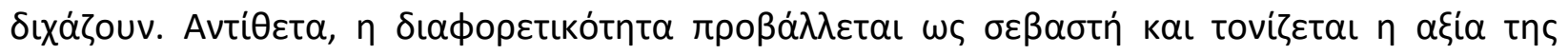

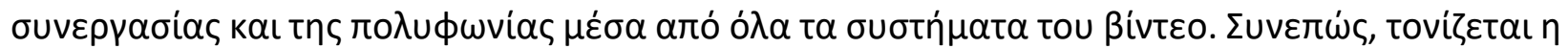

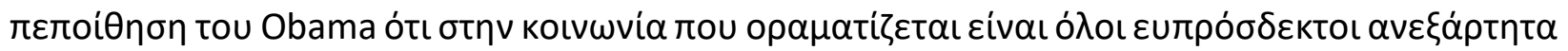

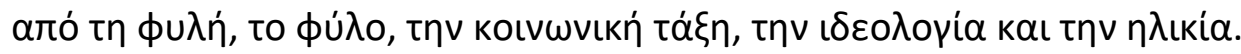

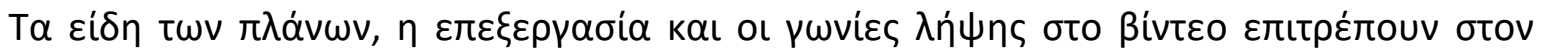

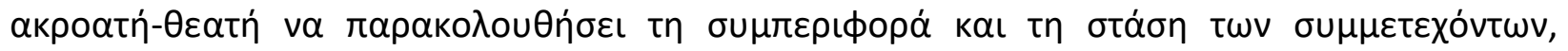

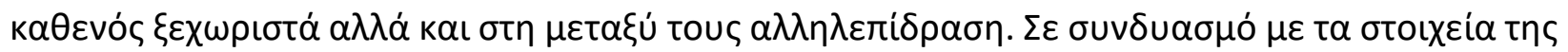

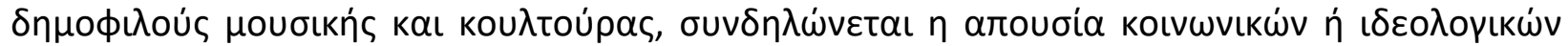

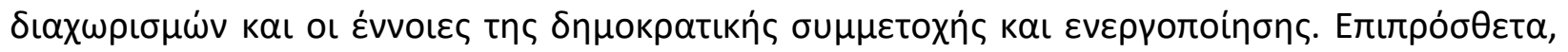

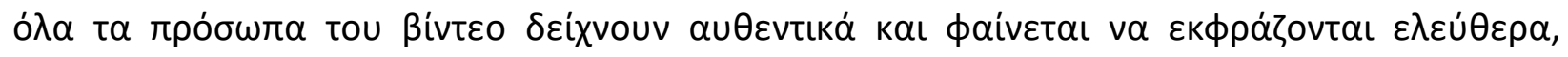

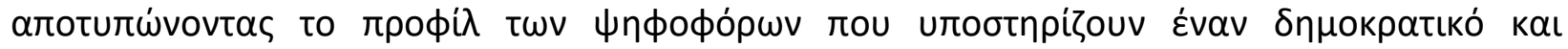

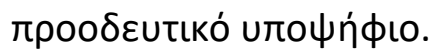


MULTILINGUAL ACADEMIC JOURNAL OF EDUCATION AND SOCIAL SCIENCES

Vol. 8 No. 1, 2020, E-ISSN: 2308-0876 @ 2020 KWP

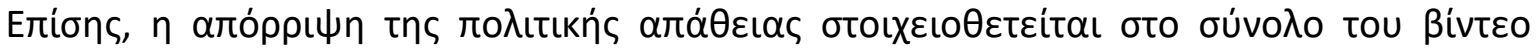

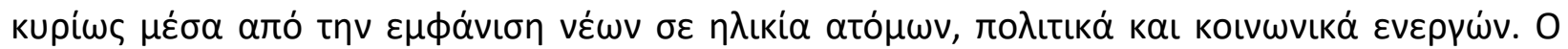

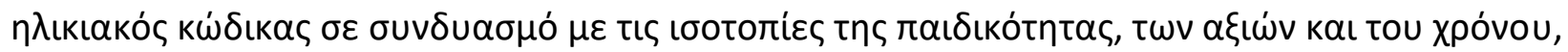

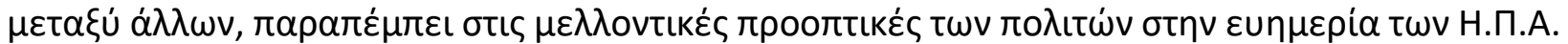

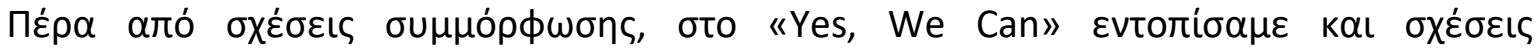

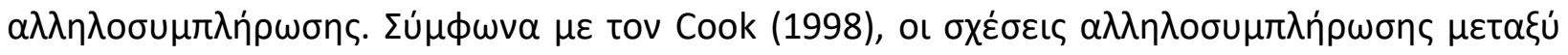

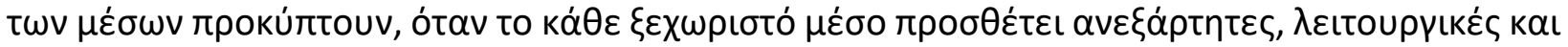

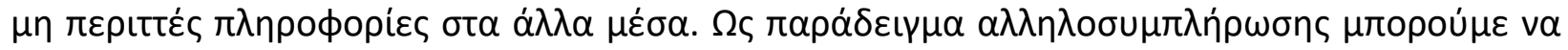

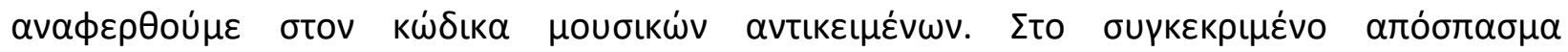

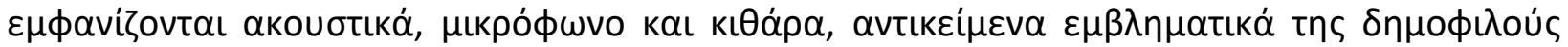

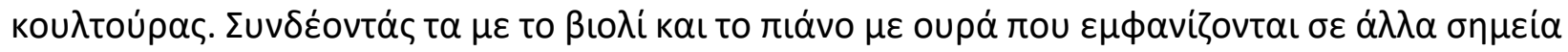

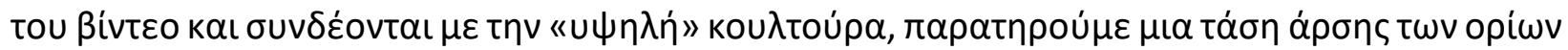

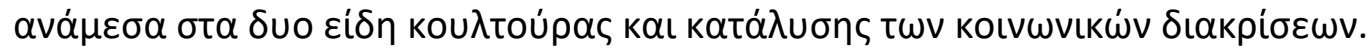

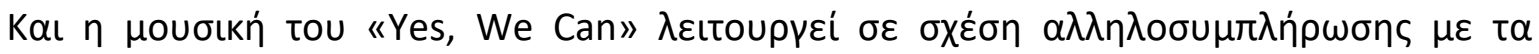

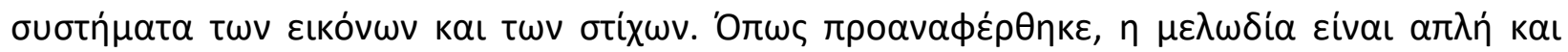

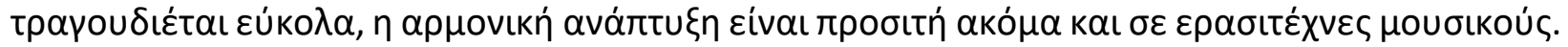

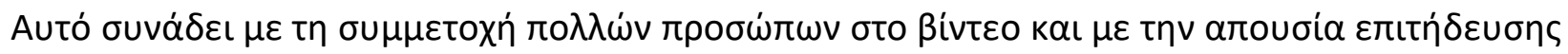

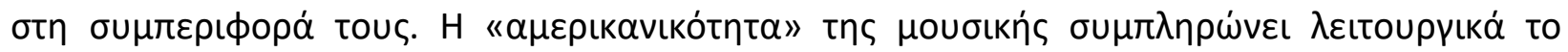

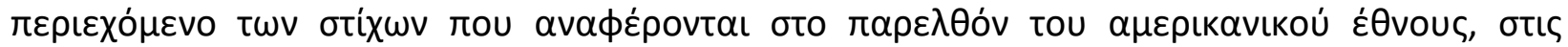

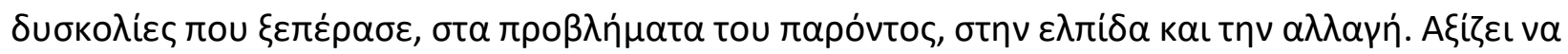

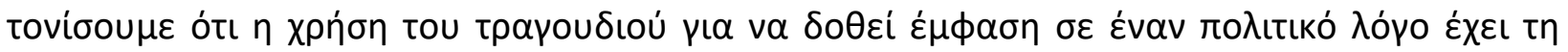

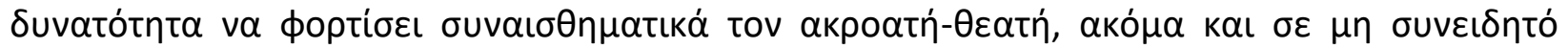

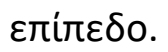

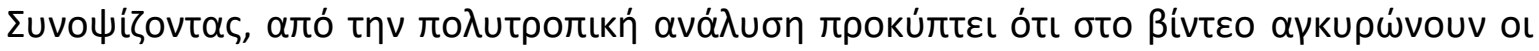

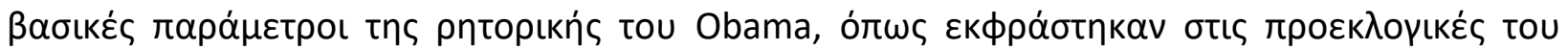

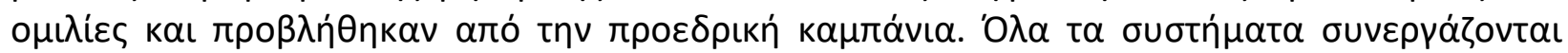

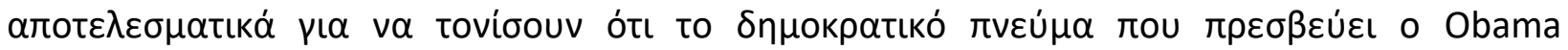

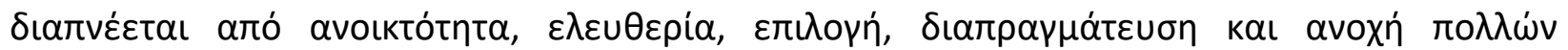

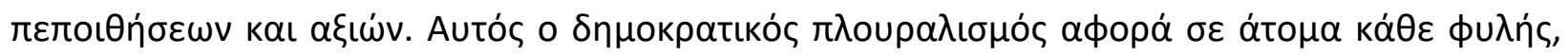

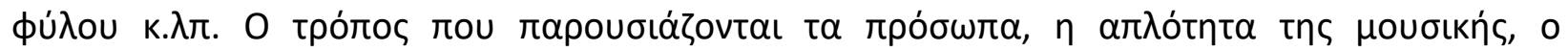

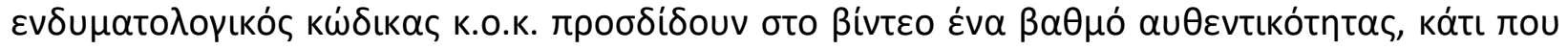

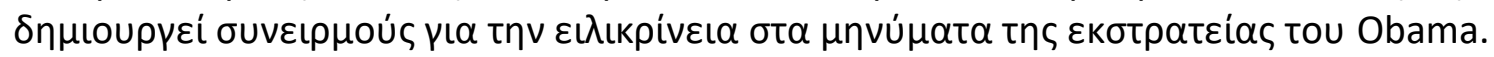

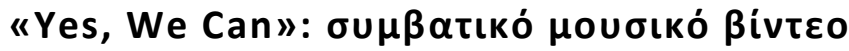

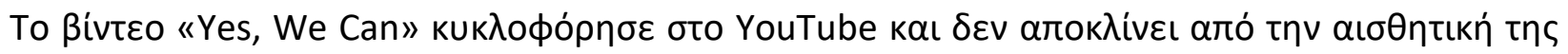

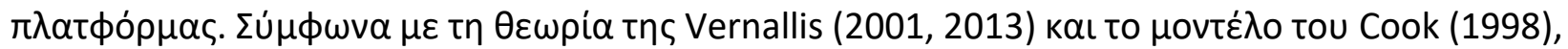

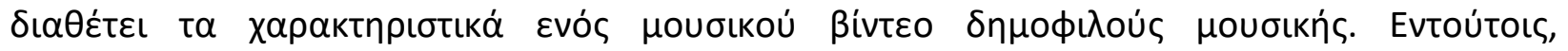

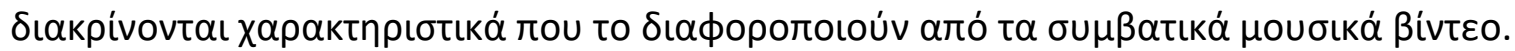

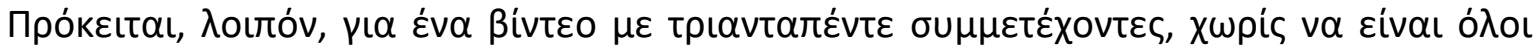

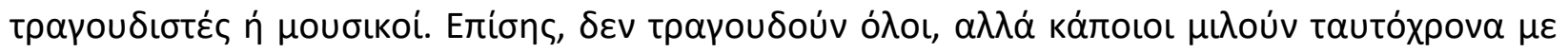

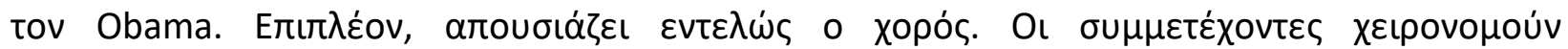

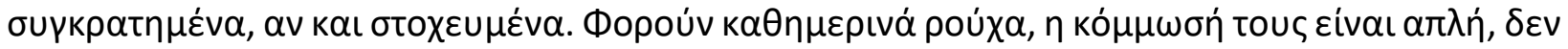

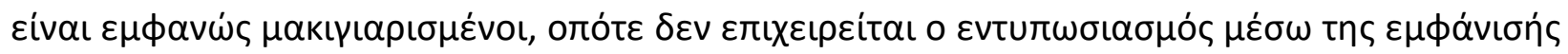

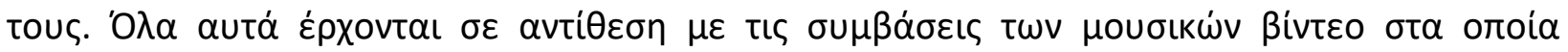


MULTILINGUAL ACADEMIC JOURNAL OF EDUCATION AND SOCIAL SCIENCES

Vol. 8 No. 1, 2020, E-ISSN: 2308-0876 @ 2020 KWP

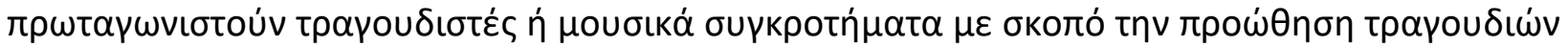

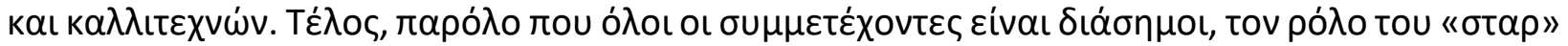

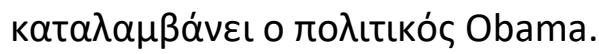

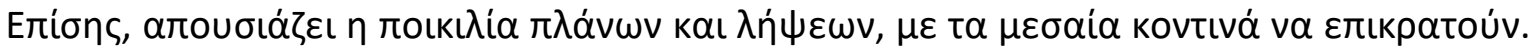

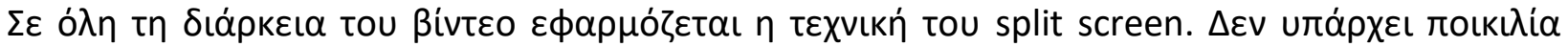

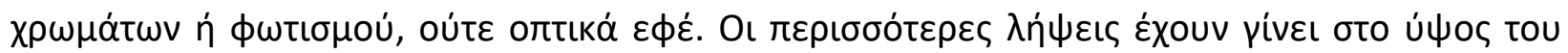

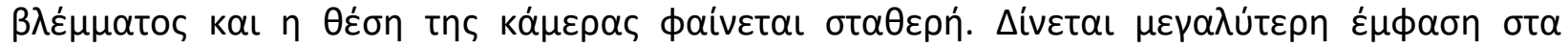

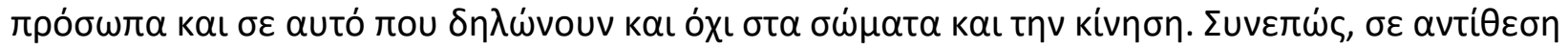

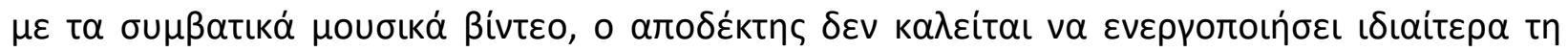

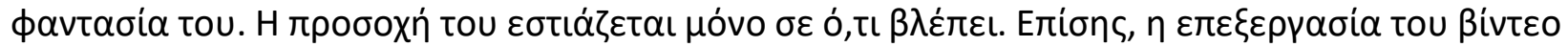

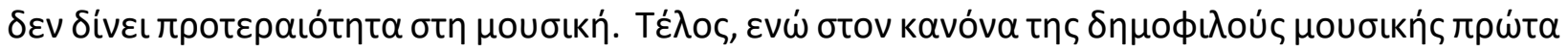

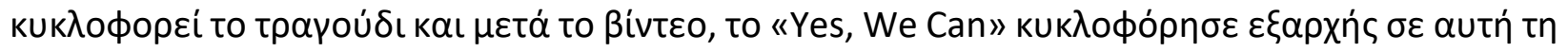
норфń.

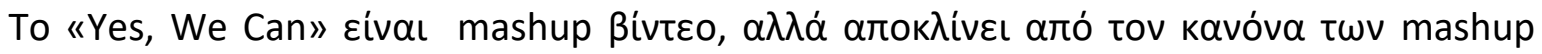

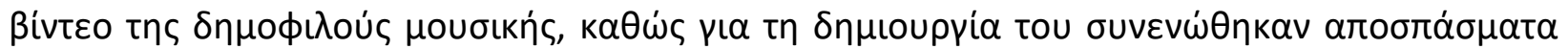

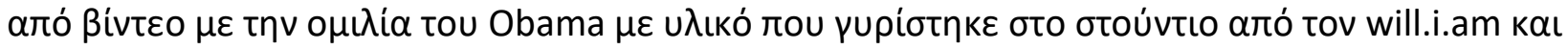

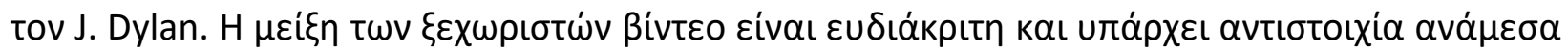

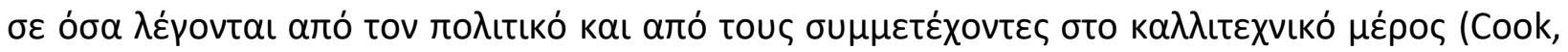

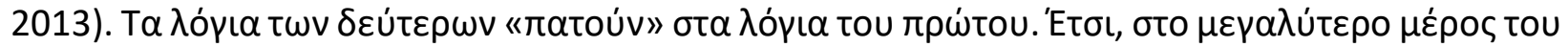

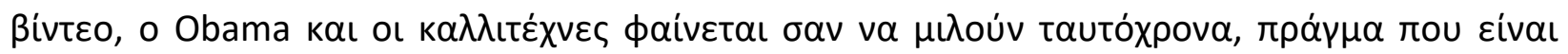

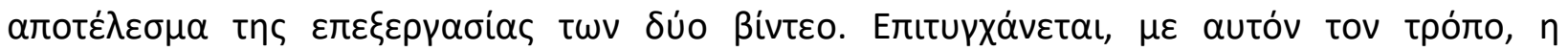

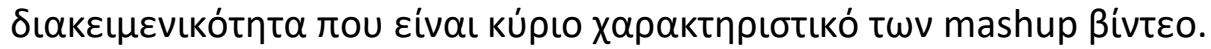

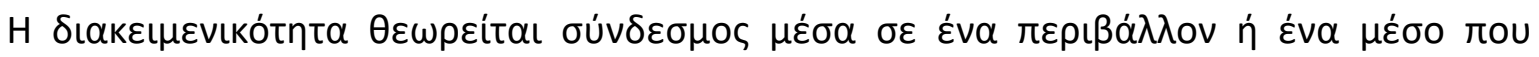

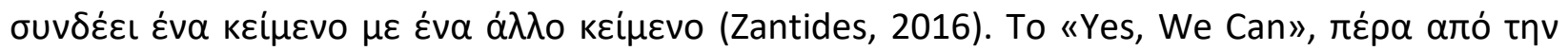

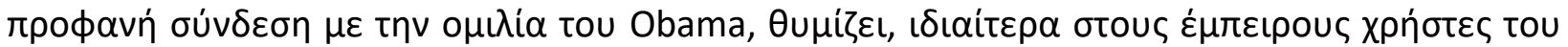

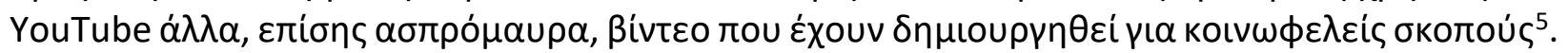

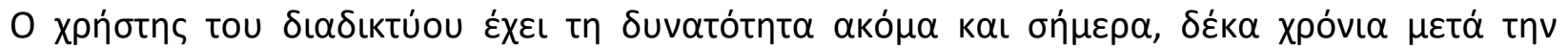

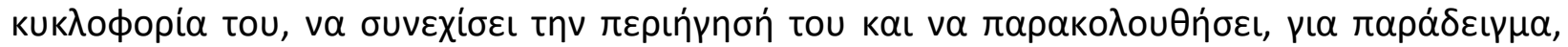

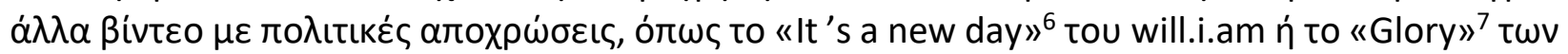
Legend kaı Common.

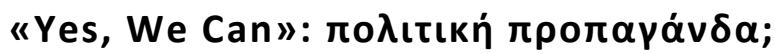

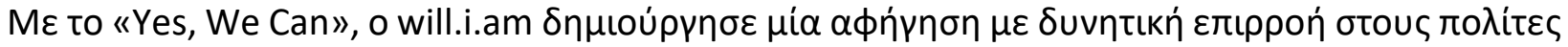

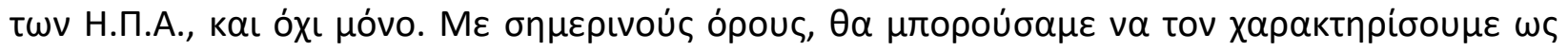

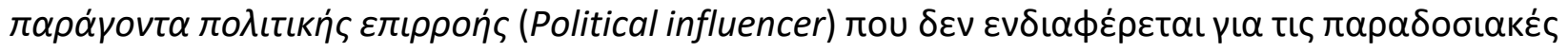

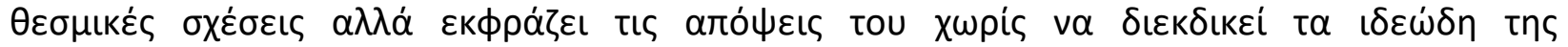

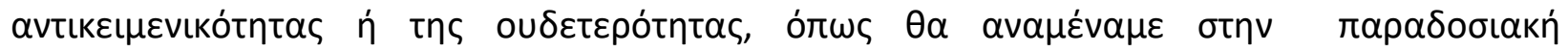

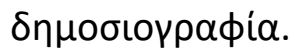

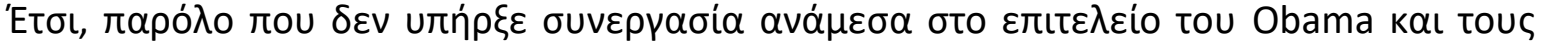

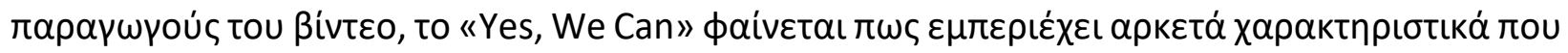

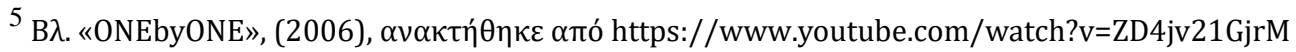

${ }^{6} \mathrm{~B} \lambda$. https://www.youtube.com/watch?v=RHWByjoQrR8

${ }^{7}$ B $\lambda$. https://www.youtube.com/watch?v=H9MKXR4gLjQ\&list=RDjjXyqcx-mYY\&index=5
} 
MULTILINGUAL ACADEMIC JOURNAL OF EDUCATION AND SOCIAL SCIENCES

Vol. 8 No. 1, 2020, E-ISSN: 2308-0876 @ 2020 KWP

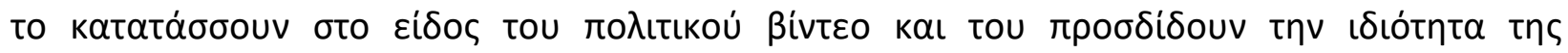

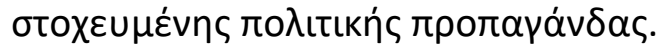

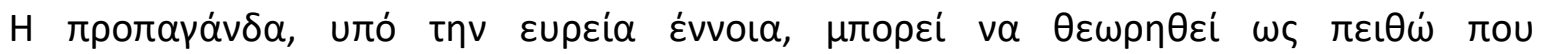

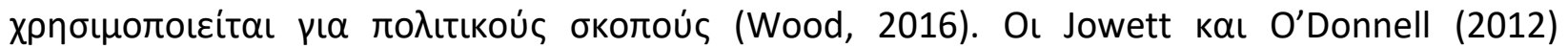

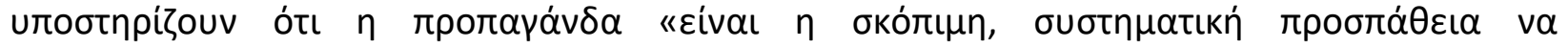

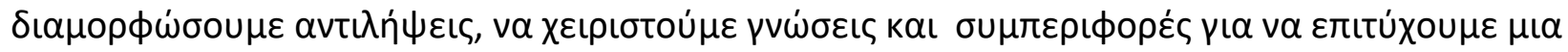

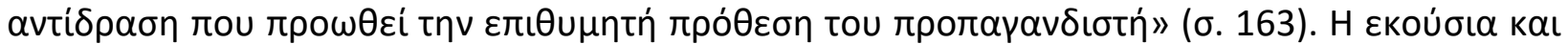

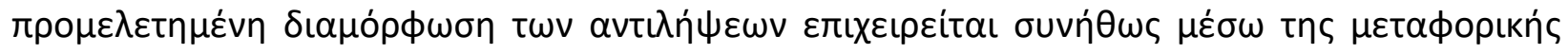

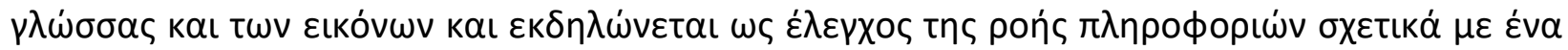

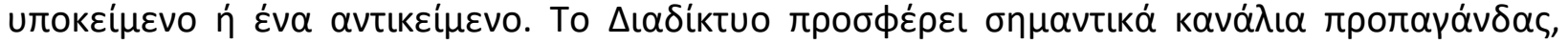

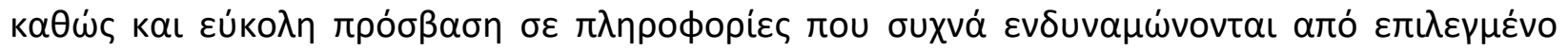

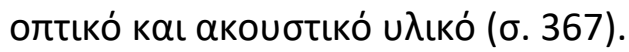

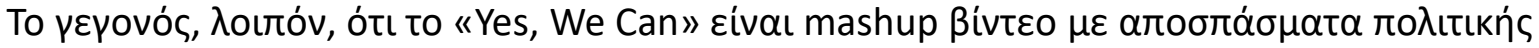

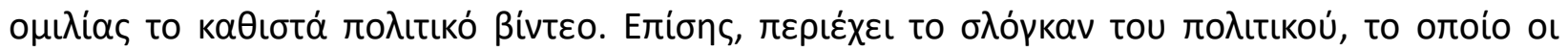

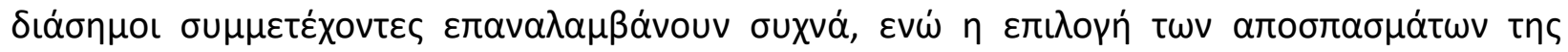

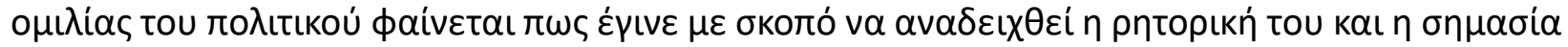

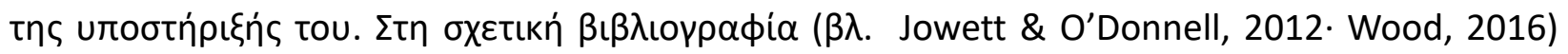

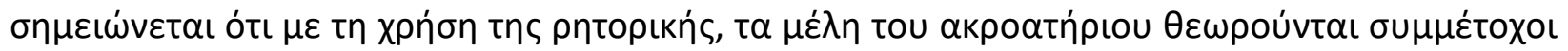

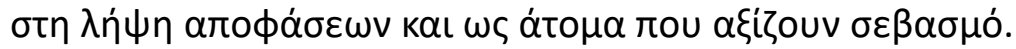

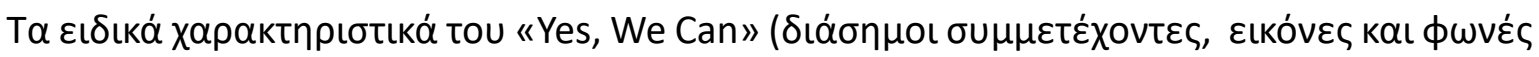

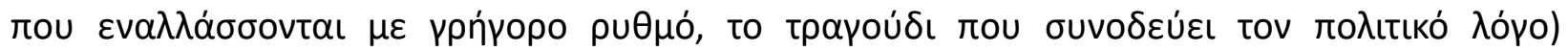

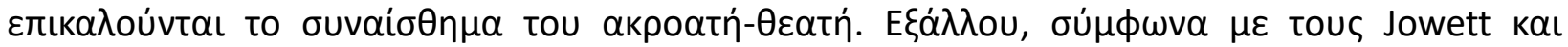

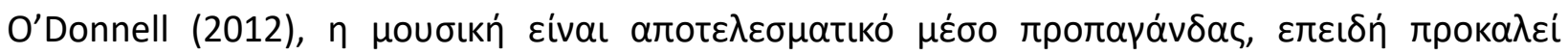

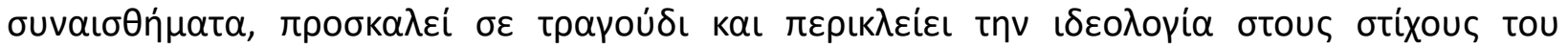

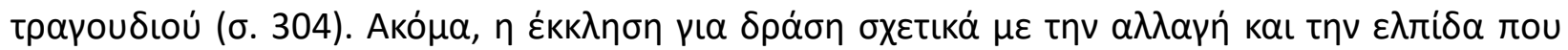

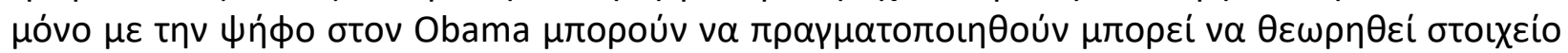

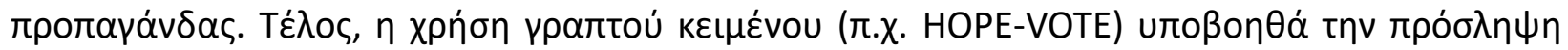

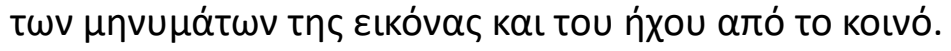

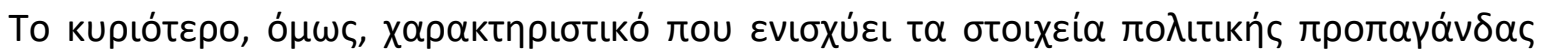

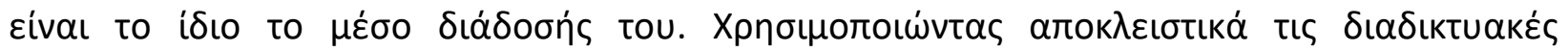

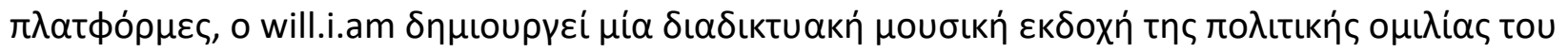

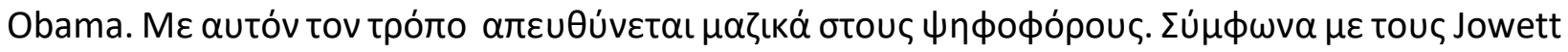

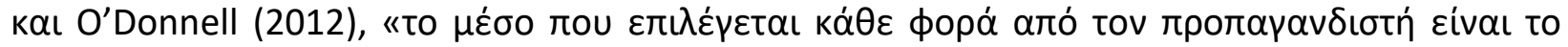

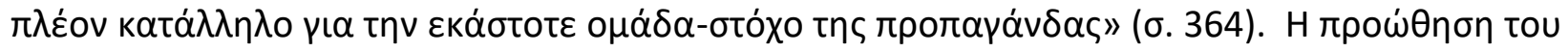

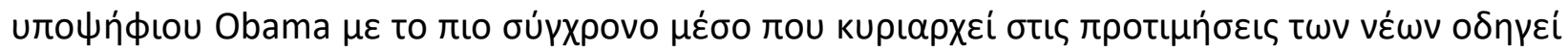

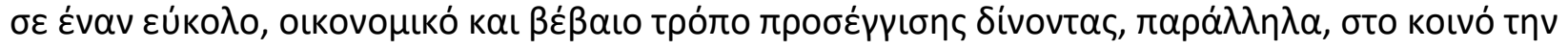

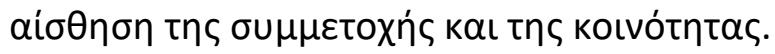

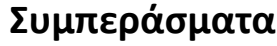

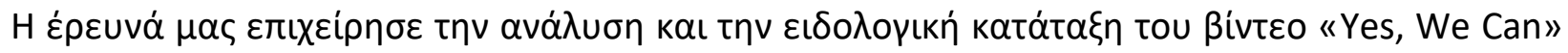

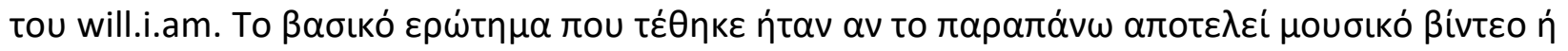

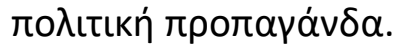

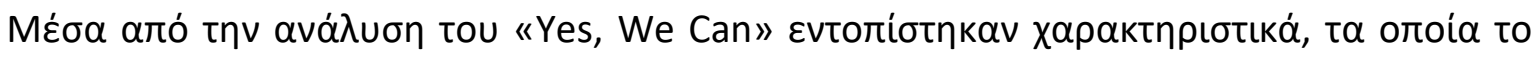

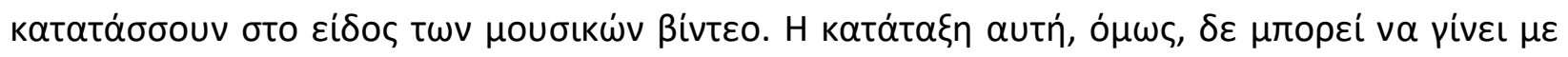




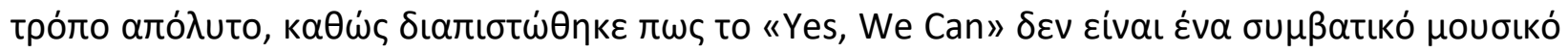

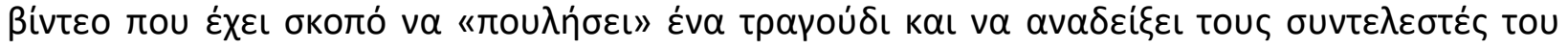

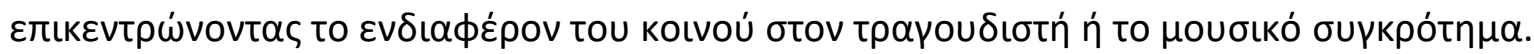

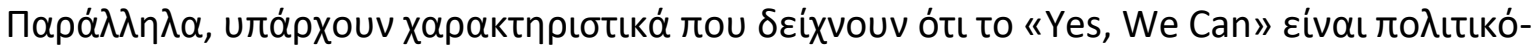

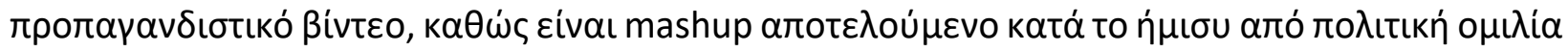

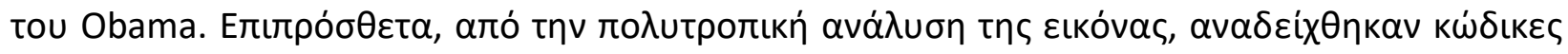

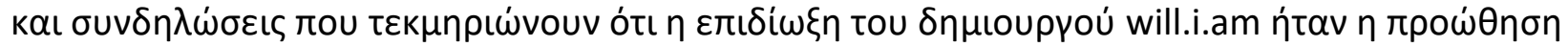
tns

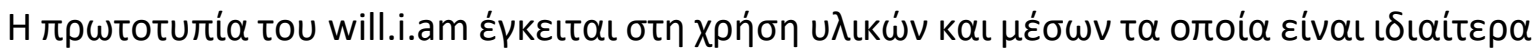

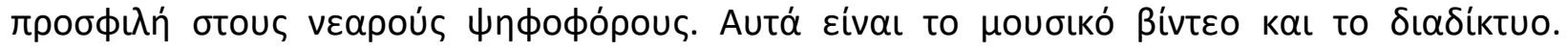

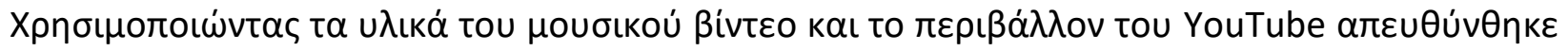

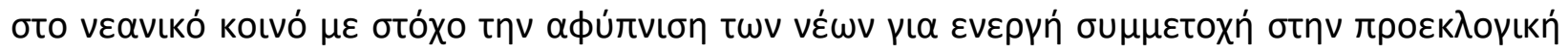

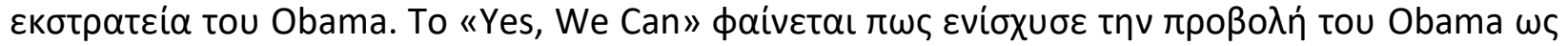

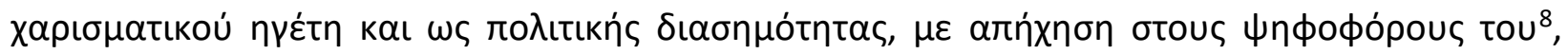

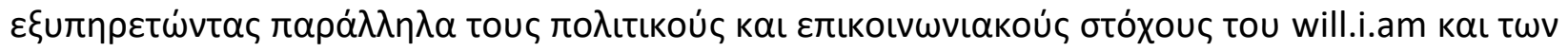

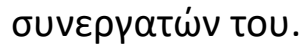

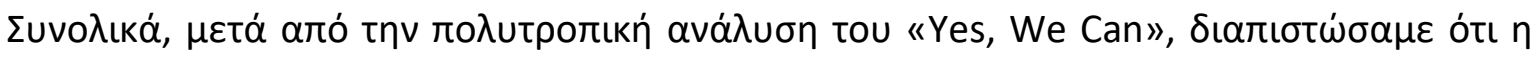

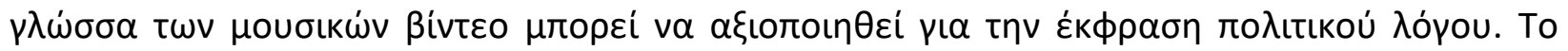

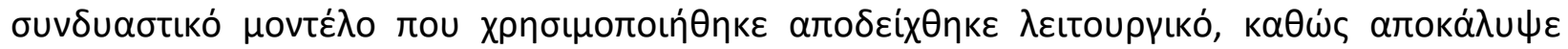

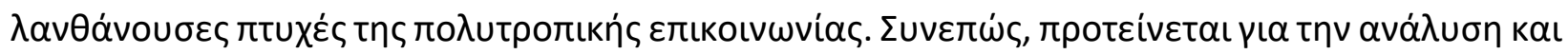

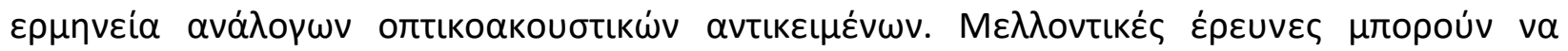

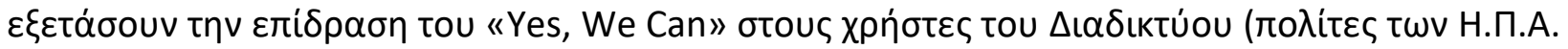

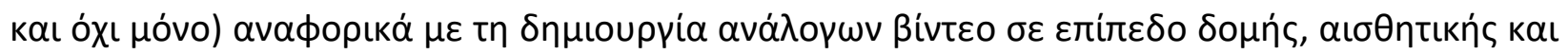
рпторькńs.

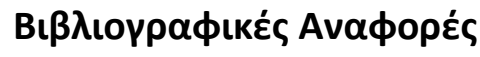

\section{References}

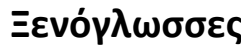

Alzgool, M. (2019). Nexus between green HRM and green management towards fostering green values. Management Science Letters, 9(12), 2073-2082.

Cook, N. (2013). Beyond Music: Mashup, Multimedia Mentality, and Intellectual Property. In J. Richardson, C. Gorbman \& C. Vernallis (Eds), The Oxford Handbook of New Audiovisual Aesthetics (pp. 56-65). New York: Oxford University Press.

Hediger, V. (2009). YouTube and the Aesthetics of Political Accountability. In P. Snickars \& P. Vonderau (Eds), The YouTube Reader (pp. 204-217). Stockholm: National Library of Sweden. Jowett, G. S., \& O'Donnell, V. (2012). Propaganda and Persuasion. Thousand Oaks, CA: Sage. (5 th $^{\text {th }}$ Edition)

Khalid, N., Islam, D. M. Z., \& Ahmed, M. R. M. (2019). Sentrepreneurial Training and Organizational Performance: Implications for Future. Humanities \& Social Sciences Reviews, 7(2), 590-593.

8 B $\lambda$. Alexovich, A. (2008, February 4). Obama Supporters Sing, 'Yes We Can'. Retreived from https://thecaucus.blogs.nytimes.com/2008/02/04/obama-supporters-sing-yes-we-can/ 
MULTILINGUAL ACADEMIC JOURNAL OF EDUCATION AND SOCIAL SCIENCES

Vol. 8 No. 1, 2020, E-ISSN: 2308-0876 @ 2020 KWP

MacGirt, E. (2008). The Brand Called Obama. Fast Company. Retrieved from https://www.fastcompany.com/754505/brand-called-obama/

Redmond, S. (2010). Avatar Obama in the age of liquid celebrity. Celebrity Studies, 1(1), pp. 8195. Retrieved from http://dx.doi.org/10.1080/19392390903519081/

Tagg, P. (2009). The Yes We Can Chords. Retrieved from: http://tagg.org/xpdfs/Yes WeCanChords.pdf

Tarasti, E. (2017). The semiotics of A. J. Greimas: A European intellectual heritage seen from the inside and the outside. Sign Systems Studies, 45(1-2), 33-53.

Umrani, W., Ahmed, U., \& Memon, P. (2015). Examining the absorptive capacity construct: A validation study in the Pakistani banking context. Management Science Letters, 5(12), 1053-1058.

Vernallis, C. (2001). Kindest Cut: Functions and Meanings of Music Video Editing. Screen, 42 (1), 21-48. Retrieved from https://doi.org/10.1093/screen/42.1.21

Vernallis, C. (2013). Unruly Media. YouTube, Music Video, and the New Digital Cinema. New York: Oxford University Press.

Wood, A. (2016). Propaganda and democracy, Theoria (Spain), 31 (3), 381-394.

Zantides, E. (2016). Visual metaphors in communication: Intertextual semiosis and déjà vu in print advertising. Romanian Journal of Communication and Public Relations, 18(3), 65-74.

Zin, M. L. M., \& Ibrahim, H. (2020). The Influence of Entrepreneurial Supports on Business Performance among Rural Entrepreneurs. Annals of Contemporary Developments in Management \& HR (ACDMHR), 2(1), 31-41.

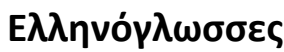

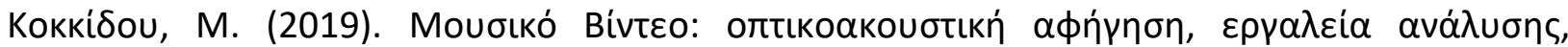

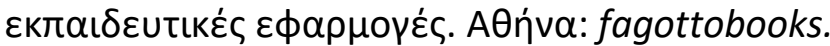

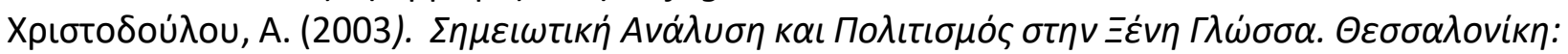
University Studio Press. 